\title{
Drk1, a Dimorphism Histidine Kinase, Contributes to Morphology, Virulence, and Stress Adaptation in Paracoccidioides brasiliensis
}

\author{
Caroline Maria Marcos ${ }^{1}$ D, Haroldo Cesar de Oliveira 1,2 ${ }^{(D}$, Patrícia Akemi Assato ${ }^{1,3}$, \\ Rafael Fernando Castelli ${ }^{2,4}{ }^{(D}$, Ana Marisa Fusco-Almeida ${ }^{1}$ and Maria José Soares Mendes-Giannini ${ }^{1, *(D)}$
}

1 School of Pharmaceutical Sciences, São Paulo State University (UNESP), Araraquara 14800-903, Brazil; marcos_caroline@yahoo.com.br (C.M.M.); haroldocdoliveira@gmail.com (H.C.d.O.); patricia.assato@gmail.com (P.A.A.); ana.marisa@uol.com.br (A.M.F.-A.)

2 Instituto Carlos Chagas, Fundação Oswaldo Cruz (Fiocruz), Curitiba 81350-010, Brazil; rafaelf.castelli@gmail.com

3 Laboratório Central de Multiusuários, Faculdade de Ciências Agronômicas, Campus Botucatu, UNESP_Universidade Estadual Paulista, São Paulo 18610-034, Brazil

4 Programa de Pós-Graduação em Biologia Parasitária, Instituto Oswaldo Cruz, Fundação Oswaldo Cruz (Fiocruz), Rio de Janeiro 21040-360, Brazil

* Correspondence: maria.giannini@unesp.br

check for updates

Citation: Marcos, C.M.; de Oliveira, H.C.; Assato, P.A.; Castelli, R.F.; Fusco-Almeida, A.M.; Mendes-Giannini, M.J.S. Drk1, a Dimorphism Histidine Kinase, Contributes to Morphology, Virulence, and Stress Adaptation in Paracoccidioides brasiliensis. J. Fungi 2021, 7, 852. https://doi.org/ $10.3390 /$ jof7100852

Academic Editor: David S. Perlin

Received: 20 August 2021

Accepted: 27 September 2021

Published: 12 October 2021

Publisher's Note: MDPI stays neutral with regard to jurisdictional claims in published maps and institutional affiliations.

Copyright: (c) 2021 by the authors. Licensee MDPI, Basel, Switzerland. This article is an open access article distributed under the terms and conditions of the Creative Commons Attribution (CC BY) license (https:/ / creativecommons.org/licenses/by/ $4.0 /)$.

\begin{abstract}
P. brasiliensis is a thermally dimorphic fungus belonging to Paracoccidioides complex, causative of a systemic, endemic mycosis limited to Latin American countries. Signal transduction pathways related to important aspects as surviving, proliferation according to the biological niches are linked to the fungal pathogenicity in many species, but its elucidation in $P$. brasiliensis remains poorly explored. As Drk1, a hybrid histidine kinase, plays regulators functions in other dimorphic fungi species, mainly in dimorphism and virulence, here we investigated its importance in P. brasilensis. We, therefore generated the respective recombinant protein, anti-PbDrk1 polyclonal antibody and a silenced strain. The Drk1 protein shows a random distribution including cell wall location that change its pattern during osmotic stress condition; moreover the P. brasiliensis treatment with anti-PbDrk1 antibody, which does not modify the fungus's viability, resulted in decreased virulence in G. mellonella model and reduced interaction with pneumocytes. Down-regulating $\mathrm{Pb}$ DRK1 yielded phenotypic alterations such as yeast cells with more elongated morphology, virulence attenuation in G. mellonella infection model, lower amount of chitin content, increased resistance to osmotic and cell wall stresses, and also caspofungin, and finally increased sensitivity to itraconazole. These observations highlight the importance of PbDrk1 to P. brasiliensis virulence, stress adaptation, morphology, and cell wall organization, and therefore it an interesting target that could help develop new antifungals.
\end{abstract}

Keywords: dimorphism regulating-histidine kinase; Drk1; Paracoccidioides brasiliensis; antisense-RNA silencing; cell wall; virulence

\section{Introduction}

The capacity to survive inside the mammalian host is a feature that is undoubtedly a condition that requires a radical change to pathogens that live in the host environment [1]. The morphogenetic adaptation known as dimorphism allows both, i.e., growth in the environment and host colonization, critical for the lifecycle of dimorphic fungi [2,3]. Among the dimorphic fungi, six phylogenetically related ascomycetes genus in the order Onygenales, Blastomyces, Histoplasma, Coccidioides, Sporothrix, Talaromyces, and Paracoccidioides, change their morphologies once spores are inhaled and reach the lungs (or at $37^{\circ} \mathrm{C}$ ), from mycelia in the environment temperature to pathogenic yeasts form [1]. 
Paracoccidioides spp. are the most important to Latin America due to the endemic aspects of paracoccidioidomycosis (PCM), a life-threatening invasive disease caused by this genre $[4,5]$. The dimorphic nature of Paracoccidioides spp. has been well-known for decades, however, the molecular mechanisms related to the dimorphism process have not been fully elucidated. The morphological changes from the mycelium to the yeast form are essential for the development and establishment of disease in the host. These changes are related to the cell wall, that it can act as a shield to prevent host recognition, and essential to developing a protective immune response [6] that can significantly contribute to infection control [7].

The detection of specific environment signals occurs through signaling pathways [8] and can alter gene expression and protein synthesis, changing the content and architecture of the cell wall [9]. Comprehension of fungi management to perceive and process abiotic and biotic factors contributing to their interaction with the environment is of great importance, specially the two-component signaling systems that can be involved in countless aspects as biological roles, general responses to different types of stress, metabolism, morphological switches, and pathogenicity [10].

The Hog1 MAP kinase belonging to the HOG (high-osmolarity glycerol) pathway, senses and responds to both osmotic and oxidative stresses, adapting the fungus to these unfavorable conditions; furthermore, it acts in fungal homeostasis, regulating the cell wall biosynthesis [11].

The two-component signal transduction system (TCST) comprises a hybrid histidine kinase, a protein that has both, histidine kinase and receiver domains [12] that senses environmental stimulus and leads to the autophosphorylation on histidine residues, afterward a phosphoryl transfer reaction to the receiver domain on aspartate residues; the latter acts like a transcription factor activating several genes related to stress adaptation, spore formation, cell-cell communication, virulence factors, and others [13].

Drk1 (dimorphism regulating histidine kinase 1) is considered a variant of the TCS, it is expected to be part of the HOG signaling pathway, facilitating the fungi adjustment to "stressful" conditions, as oxidative, osmotic, and temperature oscillations [14], but the exact stimulus that Drk1 senses still needs to be investigated.

Drk1 is described as a homolog to $\operatorname{Sn} 1$ in Saccharomyces cerevisiae [15]. The hybrid kinase components can be encoded by DRK1 and a homolog to SLN1 in most dimorphic fungi, and in some cases have both SLN1 and DRK1, in which the importance and role of each one can vary according to the species. According to Catlett et al. [16] that described six groups of HHKs (hybrid histidine kinases), $\operatorname{Sln} 1$ is classified in the transmembrane group of VI HHKs [16,17] and Drk1 belongs to the group III of HHKs and seems to be associated with the MAPK cascade, regulating the adaptation to osmotic conditions through Hog1 activation $[18,19]$.

Nemecek et al. [1] provide a piece of evidence to the morphological transition regulation through a screening of insertional mutagenesis for regulators of the BAD1 (Blastomyces adhesin-1), a yeast phase-specific gene of Blastomyces, where they identified the Drk1, a transmembrane hybrid histidine kinase, that besides acting in the control of dimorphism also govern the virulence control in B. dermatitidis and Histoplasma capsulatum.

DRK1-knockdown confers to B. dermatitidis and H. capsulatum impairment in the mycelium to yeast conversion, forming only pseudohyphae. The silenced strains showed a reduced amount of 1,3 $\alpha$-glucan, aberrant chitin distribution, increased sensibility to cell wall stressors, defects related to the expression of important virulence factor, as well as virulence attenuation [1].

Talaromyces (Penicillium) marneffei has both, DrkA and SlnA homologs to Drk1 and Sln1, respectively. Boyce et al. [20] using a single and double-deletion mutants demonstrated a partial overlap and single roles on the growth and development of the fungus. The osmotic stress adaptation and yeast grown in vivo requires both DRKA and SLNA, and both deletion results in abnormalities in the cell wall; moreover, $\operatorname{Sn} \mathrm{A}$ is required for conidia germination and DrkA to dimorphism switching during macrophage infection. 
Sporothrix schenckii demonstrated an increased expression of DRK1 in the yeastphase [21] and its silencing resulted in alterations of cell wall composition and integrity, melanin synthesis, yeast-cell phase formation, and transcription of STE20, a gene related to the HOG pathway, that together also alters the fungal pathogenicity in a murine model [22].

In P. brasiliensis, the signaling pathways that govern morphological conversion and pathogenic abilities remain very little elucidated. Chaves et al. [23] demonstrated a high expression of Drk1 transcripts by qPCR in the yeast and the transition to mycelium form in a high virulent isolate of $P$. brasiliensis obtained after passage into the animal, suggesting its importance to the morphology and virulence of this fungus. Drk1 seems to be involved in several aspects as fungal response to changes in the environment, leading to consequences like cell wall alterations and dimorphic transition, which together impact the fungal infection by dimorphic fungi.

Exploring the cell signaling pathways in virulent fungi is important due to their implications in pathogenicity regulation [24]. Therefore, to better understand the roles of Drk1 in P. brasiliensis we employed different molecular approaches as recombinant protein, antibody, and a silenced strain construction to evaluate its localization, influence on morphology, virulence, cell wall organization, and stress adaptation.

\section{Materials and Methods}

\subsection{P. brasiliensis Isolate and Culture Conditions}

P. brasiliensis isolate $(\mathrm{Pb} 18)$ was maintained on solid Fava-Netto medium before the assays were cultivated in liquid brain-heart-infusion (BHI) medium supplemented with $1 \%$ glucose in a shaker under $150 \mathrm{rpm}$ of agitation for $72 \mathrm{~h}$ at $37^{\circ} \mathrm{C}$. The number of viable yeast cells was determined using a dye exclusion test with trypan blue [25], and cell suspensions were used with viability greater than $90 \%$. Tests with microorganisms were carried out in the class III biosafety cabinet.

\subsection{Vector Construction, Heterologous Expression of PbDrk1 Recombinant (rPbDrk1), and Purification}

RNA sample isolated from P. brasiliensis yeast cells using TRIzol ${ }^{\circledR}$ reagent (Invitrogen Life Technologies, Carlsbad, CA, USA) according to the supplier specifications was transcribed to cDNA using RevertAid H Minus Reverse Transcriptase (Fermentas, Waltham, MA, USA). Initially, oligonucleotides (Table 1) containing NdeI and NotI restriction sites, were constructed to amplify the 3879-bp cDNA of PbDRK1 (PADG 07579) by polymerase chain reaction (PCR). PCR fragment was ligated in plasmid pGEM-T-Easy and used to transform E. coli DH5 $\alpha$ cells. Then, DRK1 fragment was cut out from pGEM-T-Easy using NdeI and NotI (Fermentas, Waltham, MA, USA) and subcloned in pET28a vector using the same restriction sites. The pET28/DRK1 construct was transformed into E. coli Rosetta. Transformants were selected on Luria-Bertani (LB) plates ( $1 \%$ tryptone, $0.5 \% \mathrm{NaCl}, 0.5 \%$ yeast extract, $1.5 \%$ agar, $\mathrm{pH} 7.5$ ) containing $30 \mu \mathrm{g} \mathrm{mL}{ }^{-1}$ kanamycin and chloramphenicol (34 $\mu \mathrm{g} \mathrm{mL}^{-1}$ ). The recombinant plasmid pET28/DRK1 was verified by PCR using oligonucleotides DRK1-F and DRK1-R (Table 1) and by restriction diagnostic through digestion with NdeI and NotI. The PCR parameters were an initial denaturation $94{ }^{\circ} \mathrm{C}$ for $4 \mathrm{~min}$, 25 cycles at $94{ }^{\circ} \mathrm{C}$ for $1 \mathrm{~min}$, annealing at $55^{\circ} \mathrm{C}$ for $1 \mathrm{~min}$, extension at $72{ }^{\circ} \mathrm{C}$ for $1 \mathrm{~min}$, and a final extension at $72{ }^{\circ} \mathrm{C}$ for $7 \mathrm{~min}$. The PCR and restriction fragments were separated and analyzed on $0.8 \%(w / g)$ agarose gel electrophoresis.

Single colonies were grown to log phase $\left(\mathrm{OD}_{600 \mathrm{~nm}}\right.$ of $\left.0.5-0.8\right)$ at $220 \mathrm{rpm}, 37^{\circ} \mathrm{C}$ in a shaker incubator in the selective medium previously described, and then gene induction was done using $0.4 \mathrm{mM}$ of isopropyl- $\beta$-D-thiogalactopyranoside (IPTG; Sigma-Aldrich, Saint Louis, MO, USA) for different incubation periods and temperatures, 1, 3, and $24 \mathrm{~h}$ at 37 and $30^{\circ} \mathrm{C}(220 \mathrm{rpm})$. For the purification of rPbDrk1, after IPTG induction bacterial cells were harvested and suspended in lysis buffer containing $10 \mathrm{mM}$ Tris- $\mathrm{HCl} \mathrm{pH}$ 8.0, $1 \mathrm{mM}$ phenyl methyl sulfonyl fluoride, and $10 \mathrm{mg} \mathrm{mL}^{-1}$ lysozyme at $4{ }^{\circ} \mathrm{C}$ for $30 \mathrm{~min}$, disrupted by sonication of 3 cycles of 2-min pulse and then centrifuged at 10,000 rpm for $45 \mathrm{~min}$. 
The clarified lysate was chromatographed using HisTrap FF crude column (GE Healthcare, Chicago, IL, USA) followed by passing the eluted fractions in Centricon filters $100 \mathrm{kDa}$ (Merck-Millipore, Burlington, MA, USA), both according to the manufacturer's specifications. The expression induction of rPbDrk1 as well as its purification were evaluated by $12.5 \%$ SDS-PAGE (sodium dodecyl sulfate-polyacrylamide gel electrophoresis) [26] and gel-protein detection by Coomassie Brilliant Blue R350 staining. Protein concentration was determined using the Bradford protein assay (Bio-Rad, Pleasanton, CA, USA).

Table 1. Oligonucleotides used in this study.

\begin{tabular}{|c|c|c|}
\hline Primers & Sequences & References \\
\hline DRK1-F & 5'-CATATGACTCGTGGTGAT-3' & Current work \\
\hline DRK1-R & 5'-GCGGCCGCGCACAGAGACAG-3' & Current work \\
\hline DRK1AS2-F & 5'-CCGCTCGAGCGGCTACCAACGGCGATGTGAC-3' & Current work \\
\hline DRK1AS2-R & 5'-GGCGCGCCCACAAATGATTGCATGGTC-3' & Current work \\
\hline DRK1AS3-F & 5'-CCGCTCGAGCGGCCTCCATCTCGACGATCT -3' & Current work \\
\hline DRK1AS3-R & 5'-GGCGCGCCTGTAGTTTGTGTCAGACT-3' & Current work \\
\hline DRK1-AS4-F & 5'-CCGCTCGAGCGGTGACACAAACTACAAAGA-3' & Current work \\
\hline DRK1-AS4-R & 5'-GGCGCGCCTCATCAATTTTCACCCTC-3' & Current work \\
\hline Hph-F & 5'-AACTCACCGCGACGTCTGTCGA-3' & [27] \\
\hline Hph-R & 5'-CTACACAGCCATCGGTCCAGA-3' & [27] \\
\hline DRK1-qPCR-F & 5'-CTTTTCCCTTTGGCGGCTACAA-3' & Current work \\
\hline DRK1-qPCR-R & 5'-ACTATCCTCCGGATTAGGTCTTCTAAC-3' & Current work \\
\hline L34-F & 5'-TCAATCTCTCCCGCGAATCC-3' & [28] \\
\hline L34-R & 5'-AGTTGGCGATTGTTGTGCGG-3' & [28] \\
\hline
\end{tabular}

\subsection{Mass Spectrometric Analysis of $r P b D r k 1$}

SDS-PAGE was carried out with the rPbDrk1 protein. The assumed recombinant protein band was cut out from the gel and subjected to sample preparation as described by Marcos et al. [29] to then analyzed by LC-MS/MS to confirm the protein identity. Extracted peptides were analyzed with amaZon SL ion trap mass spectrometer (Bruker Daltonics, Billerica, MA, USA) connected to a UFLC system (SHIMADZU-Nexera XR, Kioto, Japan) under control of HyStar software (Bruker Daltonics, Billerica, MA, USA) data acquisition. LC-MS/MS data files were converted to a mascot generic file format using DataAnalysis software (Bruker Daltonics, Billerica, MA, USA). MS data processing was performed with Proteinscape software (version 3.1, Bruker Daltonics, Billerica, MA, USA) using the Mascot algorithm (v2.3, Matrix Science, London, UK) for database searching configured with UniProtKB/Swiss-Protdatabase (https://web.expasy.org/docs/swissprot_guideline.html) 28 February 2018.

\subsection{Antibody Production}

To prepare the antigen for animals' immunization, the target protein band was removed from the SDS-PAGE gel and separated from the polyacrylamide matrix by electroelution (Bio-Rad, Pleasanton, CA, USA). Male New Zealand White rabbits (3 month's age) were immunized intradermally with $1 \mathrm{~mL}$ of equal mixture of rPbDrk1 electroeluted purified protein and Complete Freund's adjuvant. Eight subsequent immunizations, spaced every 3 days, using rPbDrk1 in an emulsion incomplete Freund's adjuvant (ratio 1:1) were given. Rabbits were exsanguinated by cardiac puncture 10 days after the last booster and the sera were purified with ammonium sulfate precipitation $(1.56 \mathrm{M}, \mathrm{pH} 5.6)$, and stored at $-20^{\circ} \mathrm{C}$ [29]. To be used as negative control, pre-immune serum was collected before the first immunization and stored under the same conditions. 


\subsection{Protein Extraction, SDS-PAGE, and Western Blotting}

P. brasiliensis yeast cells were cultured for 3 days in BHI medium plus $1 \%$ glucose at $37^{\circ} \mathrm{C}(150 \mathrm{rpm})$ for protein extraction. After the growth, cells were washed twice with cold, sterile water $\left(5000 \mathrm{rpm}, 5 \mathrm{~min}, 4^{\circ} \mathrm{C}\right)$. The resulting pellet was suspended in extraction buffer (10 mM Tris-HCl, $\mathrm{pH} 8.8$ ) containing a cocktail of proteases inhibitors, $1 \mathrm{mM}$ PMSF (phenyl methyl sulfonyl fluoride), and 1X PLAAC (pepstatin, leupeptin, aprotinin, antipain, chymotrypsin). An equal amount of glass beads was mixed to the samples and submitted to disruption alternating vortex and liquid $\mathrm{N}_{2}$ bath for $15 \mathrm{~min}$ (and eventually ice to avoid sample heating). Protein extract was centrifuged at 14,000 rpm for $15 \mathrm{~min}$, and the supernatant was stored at $-80^{\circ} \mathrm{C}$ until use. Bradford method was employed to determine the protein concentration [30].

For Western blotting, both total protein extract from P. brasiliensis and the rPbDrk1 protein were separated in $12.5 \%$ SDS-PAGE [26], wet transferred to nitrocellulose membranes overnight at $4{ }^{\circ} \mathrm{C}$ [31] and blocked with 5\% skimmed milk in PBS 0.5\% Tween 20 (PBS-T) for $2 \mathrm{~h}$. Membranes were incubated overnight with primary antibodies, anti-PbDrk1, and pre-immune antisera at different dilutions (1:50, 1:100, and 1:250) in blocking buffer, washed three times with PBS-T, followed by incubation with, anti-rabbit IgG-HRP antibody (Sigma-Aldrich, Saint Louis, MO, USA) in 1:2000 dilution for $2 \mathrm{~h}$ at room temperature (RT). Finally, the membranes were washed three times with PBS-T, and immune complexes were visualized employing 3,3'-diaminobenzidine (Sigma-Aldrich, Saint Louis, MO, USA) in the presence of $\mathrm{H}_{2} \mathrm{O}_{2}$.

\subsection{Protein Localization: Indirect Immunofluorescence and Immunogold}

To the confocal analysis, yeasts cells of $P$. brasiliensis cultivated for three days in BHI medium supplemented with $1 \%$ glucose, $37^{\circ} \mathrm{C}(150 \mathrm{rpm})$ were separated in $10^{6}$ yeast cells $\mathrm{mL}^{-1}$ suspensions and growth in two conditions: (a) without stress (BHI medium) and (b) with stress in BHI medium containing $0.15 \mathrm{M} \mathrm{NaCl}$ for $1 \mathrm{~h}\left(37^{\circ} \mathrm{C}, 150 \mathrm{rpm}\right)$. After the incubations, cultures were centrifuged, washed with PBS, fixed with $4 \%$ paraformaldehyde for $1 \mathrm{~h}$, and the cells were permeabilized by incubating for $45 \mathrm{~min}$ at RT with $1 \%$ Triton-X 100. Sedimented cells were washed three times with PBS, followed by the block with bovine serum albumin (BSA) $3 \%(w / v)$ in PBS for $1 \mathrm{~h}$ at $37^{\circ} \mathrm{C}$, and then incubated with the antiPbDrk1 antibody $\left(20 \mu \mathrm{g} \mathrm{mL}^{-1}\right.$ in blocking solution) overnight at $4{ }^{\circ} \mathrm{C}$. After $3 \times 10 \mathrm{~min}$ washes, cells were incubated with $10 \mu \mathrm{g} \mathrm{mL}^{-1}$ of the anti-rabbit-IgG Alexa-594 antibody (ThermoFisher, Carlsbad, CA, USA) in blocking buffer for $1 \mathrm{~h}$ at $37^{\circ} \mathrm{C}$. Finally, the cells were incubated with calcofluor white solution $\left(50 \mu \mathrm{g} \mathrm{mL}^{-1}\right.$ ) (Sigma-Aldrich, Saint Louis, MO, USA) in PBS for $1 \mathrm{~h}$ at RT, washed five times, and observed using the confocal microscope Carl Zeiss LSM 800 with Airscan (School of Dentistry of Araraquara, FOAr/UNESP, Araraquara, São Paulo, Brazil); the images were processed using the Software ZEN BLUE 2.3 System. A control with secondary antibody alone was performed to determine whether the secondary antibody directly binds the sample.

To the immunogold, $1 \times 10^{8} \mathrm{~mL}^{-1}$ yeast cells of $P$. brasiliensis were fixed overnight at $4{ }^{\circ} \mathrm{C}$ in fixative containing $2.5 \%$ glutaraldehyde in $0.1 \mathrm{M}$ sodium cacodylate buffer, $\mathrm{pH} 7.2$ and then sections collected on nickel grids were prepared by the electron microscopy service of the Institute of Biomedical Sciences-ICB-I, USP. The sections were blocked in buffer consisting of $1.5 \%(w / v)$ BSA and $0.05 \%$ Tween-20 $(v / v)$ in PBS (BSA/Tween 20 blocking solution), and then incubated overnight at $4{ }^{\circ} \mathrm{C}$ with anti-PbDrk1 antibody diluted 1:50 (40 $\left.\mu \mathrm{g} \mathrm{mL}^{-1}\right)$ in BSA/Tween 20 blocking solution. After washing with the same blocking solution, the grids were incubated with goat anti-rabbit IgG conjugated with $10 \mathrm{~nm}$ colloidal gold particles (Sigma-Aldrich, Saint Louis, MO, USA) diluted 1:10 in BSA/Tween 20 solution for $3 \mathrm{~h}$ at $4{ }^{\circ} \mathrm{C}$ [29]. Samples were examined using a Jeol-JEM-100 CXII $(80 \mathrm{kV})$ transmission microscope (Jeol, Tokyo, Japan) in the Multiuser Laboratory of Electron Microscopy (LMME-FMRP/USP). Negative control was performed by reacting samples with the rabbit pre-immune serum (NRS). 


\subsection{P. brasiliensis Viability after the Anti-PbDrk1 Treatment}

For testing the effect of the antibody on the viability of P. brasiliensis, $200 \mu \mathrm{L}$ of $10^{6}$ yeasts $\mathrm{mL}^{-1}$ in BHI medium plus $1 \%$ glucose were added to each well of a 96-well plate. The anti-PbDrk1 and pre-immune antisera were both added to a final concentration of $20 \mu \mathrm{g} \mathrm{mL}-1$. The plates were incubated at $37^{\circ} \mathrm{C}$ at $150 \mathrm{rpm}$, and the viability was assessed by tetrazolium salt (XTT) (Sigma-Aldrich, Saint Louis, MO, USA) reduction assay as described by Meshulam et al. [32]. As for viability control, P. brasiliensis without antibodies treatment was employed.

2.8. Inhibition Assays with Anti-PbDrk11 Antibody and Consequences to P. brasiliensis-Pneumocytes Interaction by Flow Cytometry

P. brasiliensis yeast cells were treated with $20 \mu \mathrm{g} \mathrm{mL}^{-1}$ of anti-PbDrk1 and pre-immune antibodies, separately, at $37^{\circ} \mathrm{C}, 150 \mathrm{rpm}$ for $1 \mathrm{~h}$, and then washed with PBS. The yeast cells were stained with FITC $\left(500 \mu \mathrm{g} \mathrm{mL}^{-1}\right)$ for $10 \mathrm{~min}$ at the same conditions, washed, and the inoculum adjusted to $10^{6}$ yeast cells $\mathrm{mL}^{-1}$ in Dulbecco's modified Eagle medium (DMEM). The inocula were used to infect the pneumocytes (A549 cells) monolayer (at 95\% of confluence, confirmed my microscopy) in a multiplicity of infection of 1:2, that was previously formed in 96-well plate after $24 \mathrm{~h}$ of incubation at $36.5^{\circ} \mathrm{C}, 5 \% \mathrm{CO}_{2}$ in DMEM enriched with $10 \%$ of fetal bovine serum (FSB). The infection was incubated under the same conditions described above for 2, 5, and $8 \mathrm{~h}$. Then, non-adherent yeast cells were removed through washing three times with PBS, and the attached cells were pulled out from the plates with cold PBS and a mechanical detachment with a rubber scraper, fixed with $4 \%$ paraformaldehyde, and then analyzed with FACSCanto ${ }^{\mathrm{TM}}$ (BD Biosciences, San Jose, CA, USA) cytometer using FACSDiva software [33]. To adjust the gates uninfected A549 cells and yeast cells, labeled and unlabeled, were employed. The percentage of A549 cells infected by adhered and/or internalized yeast cells was defined from FITCpositive population from the A549 gate within 10,000 acquired events.

\subsection{Effect of the P. brasiliensis Anti-PbDrk1 Antibody Treatment on G. mellonella Infection}

As well performed to the A549 cells assay, P. brasiliensis was treated with anti-PbDrk1 and pre-immune serum, and then $5 \times 10^{6}$ yeast cells (in PBS) were used to infect $G$. mellonella (weighing 0.15-0.2 g) using Hamilton syringe (Hamilton, Reno, NV, USA) through the last proleg. To observe possible consequences related to physical injury on the larvae survival, a control group was injected with PBS alone. The larvae were maintained at $37^{\circ} \mathrm{C}$ and the mortality recorded daily for one week [34].

\subsection{PbDRK1 Gene Silencing with Antisense Molecules and Agrobacterium Tumefaciens Transformation (ATMT)}

Antisense RNA (aRNA) and ATMT were employed to generate a DRK1-silenced P. brasiliensis strain $[35,36]$. Briefly, three sequences of different coding regions of the DRK1 gene comprising nucleotides between positions 112-230 (AS2), 231-333 (AS3), and 320-481 (AS4) were amplified using a high-fidelity DNA polymerase (Platinum ${ }^{\mathrm{TM}}$, ThermoFisher, Carlsbad, CA, USA) and primers DRK1-AS2-F/R, DRK1-AS3-F/R, and DRK1-AS4-F/R (ThermoFisher, Carlsbad, CA, USA) (Table 1). The inserts AS2, AS3, and AS4 were ligated individually into the pCR35 vector under the control of the calcium-binding protein (CBP-1) promoter. The pCR35 vectors containing AS2, AS3, and AS4 were subcloned into the pUR5750 parenteral binary vector and used to transform A. tumefaciens LBA1100 via electroporation. After kanamycin $\left(100 \mu \mathrm{g} \mathrm{mL}^{-1}\right)$ resistance selection and confirmation by PCR, positive $A$. tumefaciens, for pUR5750 transformation were employed in the $P$. brasiliensis yeast cells transformation through co-cultivation of both microorganisms in a 6-well culture plate at a 1:1, 1:10, and 1:100 ratios on liquid induction medium (IM) at $25^{\circ} \mathrm{C}$ for $72 \mathrm{~h}$ at agitation speed of $100 \mathrm{rpm}$ according to Goes et al., [28] with modifications. After co-cultivation, $2 \mathrm{~mL}$ of BHI supplemented with $1 \%$ glucose (BHID), $10 \%$ of FSB, and $200 \mu \mathrm{g} \mathrm{mL}{ }^{-1}$ of cefotaxime, was added and the cocultivation was incubated for another 
$48 \mathrm{~h}$ at $36^{\circ} \mathrm{C}(150 \mathrm{rpm})$ to promote the expression of the hygromycin B resistance (hph) gene and to eliminate A. tumefaciens cells. Subsequently, the cultures were centrifuged, the pellet cells suspended in $200 \mu \mathrm{L}$ of the residual IM and plated on BHID, 5\% (FSB), $100 \mu \mathrm{g} \mathrm{mL}^{-1}$ cefotaxime, and $100 \mu \mathrm{g} \mathrm{mL} \mathrm{m}^{-1}$ hygromycin. The plates were incubated at $36^{\circ} \mathrm{C}$ until the growth of $P$. brasiliensis colonies (20-25 days). Isolated colonies of P. brasiliensis transformants were transferred to liquid BHID, 5\% FBS, $100 \mu \mathrm{g} \mathrm{mL}^{-1}$ cefotaxime, and $100 \mu \mathrm{g} \mathrm{mL}^{-1}$ hygromycin in 12-well culture plate and subcultured for three successive rounds of 3 days to select only stable integrants and remove remaining untransformed yeast cells. Then, $P$. brasiliensis transformants were transferred to non-selective medium BHID, 5\% FSB and subcultured for three more successive rounds to inspect mitotic stability followed by the analysis of growth capacity in a 12-well culture plate with selective liquid BHDI, $5 \% \mathrm{FBS}$ and $100 \mu \mathrm{g} \mathrm{mL}^{-1}$ of hygromycin.

\subsection{PCR Detection of Hygromycin Resistance Gene (hph) and Analysis of PbDRK1 Transcript Levels by qRT-PCR (Quantitative Real Time PCR)}

First, we evaluated the insertion and retention of T-DNA in the hygromycin resistant colonies of P. brasiliensis by direct PCR as described by Goes et al. [28]. The PCR detection of hph gene was carried out with a $50 \mu \mathrm{L}$ reaction mixture consisting of $5 \mu \mathrm{L}$ of cell lysate, $0.4 \mu \mathrm{M}$ of primers hph-F/R (Table 1), 1.25 units of Taq polymerase, $0.2 \mathrm{mM}$ dNTP, $2 \mathrm{mM}$ $\mathrm{MgCl}_{2}$, and Taq buffer. The PCR reactions were run with cycling protocol of $4 \mathrm{~min}$ at $94{ }^{\circ} \mathrm{C}$, followed by 35 cycles of $30 \mathrm{~s}$ at $94{ }^{\circ} \mathrm{C}, 1 \mathrm{~min}$ at $52{ }^{\circ} \mathrm{C}, 2 \mathrm{~min}$ at $72{ }^{\circ} \mathrm{C}$, and final extension for 10 min at $72{ }^{\circ} \mathrm{C}$.

After detecting the hph gene in the P. brasiliensis-transformants, the DRK1 gene expression was determined by qRT-PCR. RNA was extracted from yeast cells of PbWT (P. brasiliensis wild-type), PbEV (P. brasiliensis transformed with empty vector), $\mathrm{PbDRK1}$ aRNA2, PbDRK1 aRNA3, and PbDRK1 aRNA4. P. brasiliensis transformed with aRNA cassettes AS2, AS3, and AS4, respectively, using TRIzol ${ }^{\circledR}$ (Invitrogen Life Technologies, Carlsbad, CA, USA) and glass beads maceration was treated with DNAseI (ThermoFisher, Carlsbad, CA, USA) after RNA purity assessment. The cDNA was synthesized from $1 \mu \mathrm{g}$ of RNA using the RevertAid ${ }^{\mathrm{TM}} \mathrm{H}$ Minus Reverse Transcriptase (Fermentas, Waltham, MA, USA). Real-time PCR was carried out using the QuantiNova SYBR Green PCR kit with ROX, according to the manufacturer (Qiagen, Hilden, Germany). The 7500 Cycler Real-Time PCR System (Applied Biosystems ${ }^{\circledR}$, Whaltham, MA, USA) was employed to the qRT-PCR assay. The sequences of the DRK1-qPCR-F/R primers used to detect the DRK1 mRNA expression levels are shown in Table 1. qRT-PCR melt curve was assessed to verify the single peaks [37]. Data were analyzed using the $2^{-\Delta \Delta C t}$ method [38] using L34 gene (primers in Table 1) as endogenous control, and the target gene expression levels in PbWT and $\mathrm{PbEV}$ as calibrators.

\subsection{Phenotypic Effects of PbDRK1 Silencing \\ 2.12.1. Growth Curve and Cell Viability}

Inoculum of the strains, $\mathrm{PbWT}, \mathrm{PbEV}, \mathrm{PbDRK1}$ aRNA2, $\mathrm{PbDRK} 2$ aRNA3, and PbDRK1 aRNA4 were adjusted to start the growth curve with $10^{5}$ cells $\mathrm{mL}^{-1}$ in $100 \mathrm{~mL}$ of BHI liquid medium with $1 \%$ glucose at $37^{\circ} \mathrm{C}(150 \mathrm{rpm})$. Growth was assessed by spectrophotometric analysis $\left(\mathrm{OD}_{600 \mathrm{~nm}}\right.$; Epoch2, BioTek, Winooski, VT, USA) at $24 \mathrm{~h}$ intervals for 7 days. At times of 0 and $168 \mathrm{~h}$, a sample was taken for viability assay with trypan blue dye, according to Marcos et al. [39].

\subsubsection{Morphological Analysis}

Yeast cells of PbWT, PbEV, PbDRK1 aRNA2, PbDRK1 aRNA3, and PbDRK1 aRNA4 were grown under standard conditions as mentioned above. Then, the cells were washed with PBS and then fixed with $2.5 \%$ glutaraldehyde in a $0.1 \mathrm{M}$ sodium cacodylate buffer ( $\mathrm{pH} 7.2$ ) for $1 \mathrm{~h}$ at $25^{\circ} \mathrm{C}$. After washing with sodium cacodylate buffer containing $0.2 \mathrm{M}$ sucrose and $2 \mathrm{mM} \mathrm{MgCl}$, the cells were seeded on poly-D-lysine $(0.01 \%)$ and covered 
with coverslips and incubated for $30 \mathrm{~min}$ at $25{ }^{\circ} \mathrm{C}$. A series of gradual ethanol dehydration $(30,50$, and $70 \%$ for $5 \mathrm{~min}, 90 \%$ for $10 \mathrm{~min}$, and 100\% twice for $10 \mathrm{~min}$ ) was performed followed by a critical-point drying (LEICA EM CPD300, Wetzlar, Germany), and mounting on metallic bases to be covered with a gold layer [40]. Images were obtained using a scanning electron microscope (JEOL JSM-6010 Plus/LA) operating at $5 \mathrm{keV}$.

\subsubsection{Virulence Assay}

To evaluate the effects of the DRK1 silencing in P. brasiliensis-virulence, we employed the G. mellonella model of infection with $\mathrm{PbWT}, \mathrm{PbEV}$, and $\mathrm{PbDRK1}$ aRNAs strains. The infection was performed as described above.

\subsubsection{Chitin Level}

All strains were cultured for $72 \mathrm{~h}$ at $37^{\circ} \mathrm{C}(150 \mathrm{rpm})$ in BHI medium with $1 \%$ glucose. Then, aliquots of each strain were fixed with $4 \%$ paraformaldehyde, and the cell concentration was adjusted to $10^{6}$ cells $\mathrm{mL}^{-1}$ after PBS-washing. The suspensions were stained with $50 \mu \mathrm{g} \mathrm{mL}^{-1}$ calcofluor white (CFW) (ThermoFisher, Carlsbad, CA, USA), a specific chitin dye, for $1 \mathrm{~h}$ at RT. After staining, the yeast cells were washed three times, and the cell suspension was placed on a glass slide and observed under a fluorescent microscope DMi8 (Leica, Wetzlar, Germany), with the same laser exposure time, coupling with the acquisition image system LasAF. The fluorescence intensity (at least 50 yeast cells) was determined using ImageJ, and the results expressed as a mean of fluorescence intensity/area of the yeast cell.

\subsubsection{Susceptibility to Antifungals}

Strains were tested for their antifungal susceptibility to itraconazole (ITZ) (SigmaAldrich, Saint Louis, MO, USA) and caspofungin (CSP) (Sigma-Aldrich, Saint Louis, MO, USA) according to CLSI (Clinical and Laboratory Standards Institute) document M27-A3 with some modifications [41]. The inocula containing $10^{6}$ cells $\mathrm{mL}^{-1}$, prepared with a 4-days culture in Fava-Netto medium at $37^{\circ} \mathrm{C}$, were diluted 1:50 in PBS and then 1:20 in RPMI 1640 medium (Gibco; ThermoFisher Scientific, Carlsbad, CA, USA) supplemented with $2 \%$ glucose (RPMI-2\% gluc), giving a final concentration of 0.5 to $2.5 \times 10^{3}$ cells $\mathrm{mL}^{-1}$ after antifungals addition. ITZ and CSP were prepared in RPMI-2\% gluc. The final concentrations of ITZ and CSP varied from 0.0000625 to $0.032 \mu \mathrm{g} \mathrm{mL}^{-1}$ and 0.0625 to $32 \mu \mathrm{g} \mathrm{mL}{ }^{-1}$, respectively. The plates were incubated for $48 \mathrm{~h}$ at $37^{\circ} \mathrm{C}(150 \mathrm{rpm})$ and the viability was assessed using Alamar Blue (BioSource International, Camarillo, CA, USA), which has been added and incubated in the same conditions for $24 \mathrm{~h}$ [41]. The viability was assessed through absorbance evaluation at 570 and $600 \mathrm{~nm}$.

\subsubsection{Susceptibility to Cell Wall Stresses}

$\mathrm{NaCl}$ and Congo Red sensibility were performed through spot assay [42]. Inocula containing 107 cells $\mathrm{mL}^{-1}$ were prepared with strains grown for 4-days in Fava-Netto medium at $37^{\circ} \mathrm{C}$, and then undiluted culture and a ten-fold serial dilution of culture were spotted on YPD plates supplemented with Congo red $\left(2.5\right.$ and $\left.5.0 \mu \mathrm{g} \mathrm{mL}^{-1} ; \mathrm{CR}\right)$ and $\mathrm{NaCl}(0.05$ and $0.15 \mathrm{M})$, respectively. After incubation at $37^{\circ} \mathrm{C}$ for 7 days, the plates were photographed.

\subsection{Statistical Analysis}

The statistical analysis was made using GraphPad Prism 5.0 (GraphPad software, Inc., La Jolla, CA, USA). One-way ANOVA followed by Tukey's test and Student's t-test were used to calculate the statistical significance. Survival curves were analyzed by Logrank test, and $p$-values of $<0.05$ were considered statistically significant. 


\section{Results}

3.1. Molecular Cloning of cDNA Encoding a DRK1 of P. brasiliensis, Expression and Recombinant Protein Purification

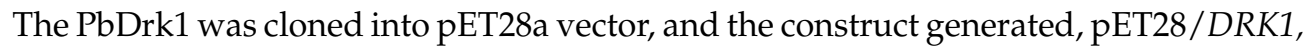
was used to transform E. coli Rosetta. Colony-PCR and double restriction analysis using the target-specific primers and NotI/NdeI enzymes, respectively confirmed the success of transformation with the clones carrying the insert of the size expected for the target Drk1 (3879 bp), as well two fragments after digestion: $\sim 5.4 \mathrm{~kb}$ representing the pET28a vector and a $\sim 3.9 \mathrm{~kb}$ fragment representing DRK1 fragment.

A soluble fraction obtained from cells grown in the presence of $0.4 \mathrm{mM} \mathrm{IPTG}$ expressed a $142.5 \mathrm{kDa}$ polypeptide with a higher expression at $37^{\circ} \mathrm{C}$ from 1 and $3 \mathrm{~h}$ of IPTG induction (Figure 1A). The condition established in the small-scale expression, $0.4 \mathrm{mM}$ of IPTG at $37^{\circ} \mathrm{C}$ by $1 \mathrm{~h}$, was employed in a large-scale production $(1 \mathrm{~L})$, and solubilized proteins were purified. It was possible to obtain a fraction containing the rPbDrk1 and a small number of contaminant proteins (Figure 1B), which have been successfully removed passing the sample in Centricon-filter (100 kDa), allowing the rPbDrk1 purification (Figure 1C).

A)

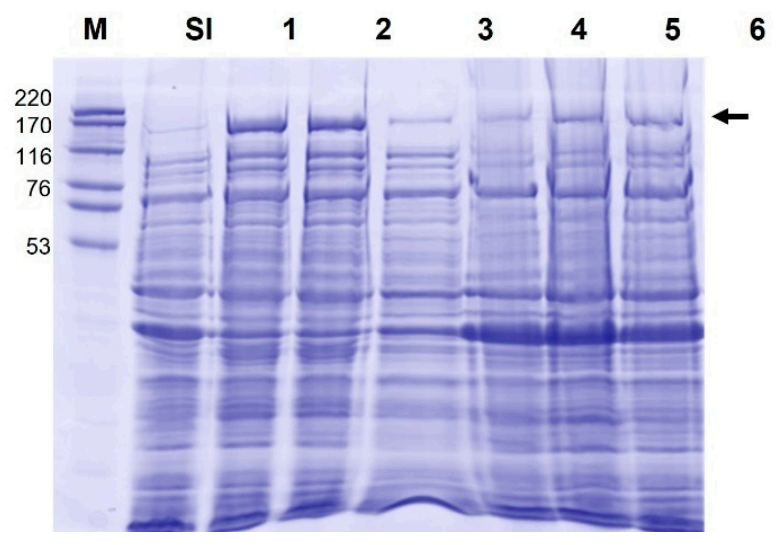

B)

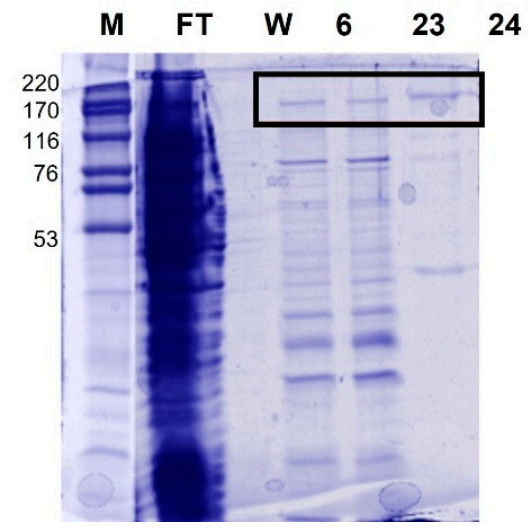

C)

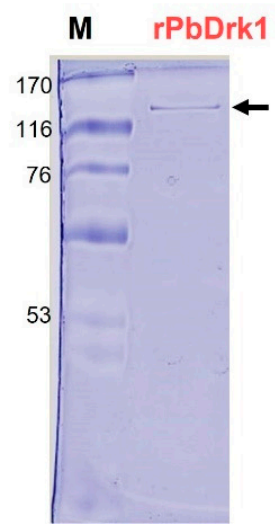

Figure 1. PbDrk1 expression and purification. (A) Expression of PbDrk1 in Escherichia coli Rosetta cells transformed with pET28/DRK1. Absence of IPTG (Lane SI); lanes 1 to 3: upon IPTG induction after 1, 3, and $24 \mathrm{~h}$ at $37^{\circ} \mathrm{C}$. Lanes 4 to 6 : upon IPTG induction after 1,3, and $24 \mathrm{~h}$ at $30^{\circ} \mathrm{C}$. (B) Protein purification after ion metal affinity chromatography (IMAC). SDS-PAGE of fractions from flow through (FT), wash (W), and 6, 23, and 24 elution fractions. (C) rPbDrk1 purified after affinity chromatography and passing by Centricon $(100 \mathrm{kDa})$. Protein bands were revealed with Coomassie Blue staining. Lane M: standard protein marker (GE Healthcare, Chicago, IL, USA, 53-220 kDa).

The single band representing the purified protein was submitted to mass spectrometric identification to confirm the identity of the rPbDrk1 and detailed results are shown in Figure S1. The rPbDRK1 protein presented a molecular mass of $142.5 \mathrm{kDa}$ and an acidic isoelectric point (pI) of 5.3. Overlapping peptides identified by mass spectrometry and amino acid sequence of PbDrk1 were possible to demonstrate a covering of $59 \%$ of the Drk1 protein (Figure S1).

\subsection{Anti-PbDrk1 Polyclonal Antibody Recognizes the rPbDRK1 and Native Protein in P. brasiliensis}

An anti-PbDrk1 rabbit polyclonal antibody was obtained through immunizing rabbits with PbDrk1 recombinant protein electro-eluted from the gel. As demonstrated in Figure 2, a single protein band on Western blotting was revealed in preparation with $\mathrm{rPbDRK} 1$ (Figure 2A) and the total protein extract of P. brasiliensis (Figure 2B) showing that the antibody was able to recognize the native protein of $P$. brasiliensis. The rabbit pre-immune serum did not react with all the samples (Figure 2A,B). 
A)

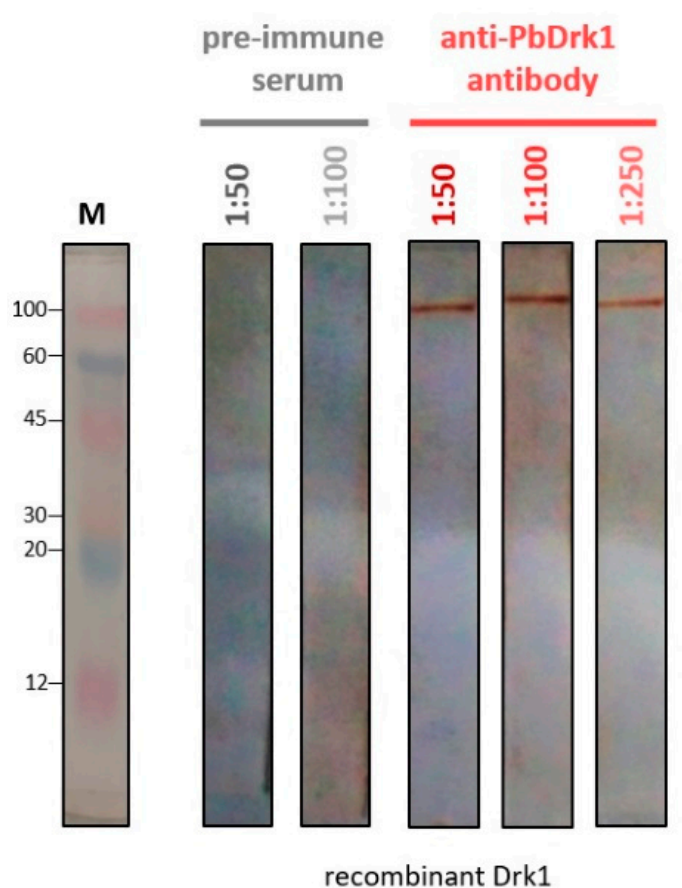

B)

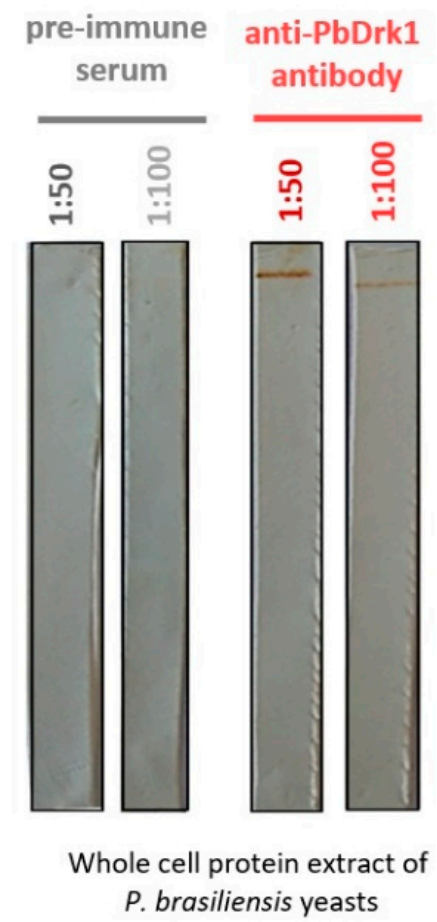

Figure 2. Western blotting of recombinant Drk1 and P. brasiliensis proteins recognized by anti-Drk1 antibody. Western blotting of (A) recombinant and (B) native Drk1 of P. brasiliensis. The non-specific reaction was evaluated using a pre-immune serum. M: standard protein marker (ColorBurst ${ }^{\mathrm{TM}}$ Sigma-Aldrich, Saint Louis, MO, USA; 8-220 kDa). The molecular mass is indicated on the left in kilodaltons $(\mathrm{kDa})$.

\subsection{PbDrk1 Localization in the Yeast Cell Surface, Showing an Altered Pattern of Expression} during Osmotic Stress Condition

The confocal microscopy images seen in Figure 3A show homogeneous fluorescence labels throughout the cell, both in the mother cells and buds, with an apparent co-localization of PbDrk1 with calcofluor white stain in the fungi cell wall. Once histidine kinases typically comprise the first sensing proteins of multistep phosphorelay signaling pathways osmosensing environmental alterations as osmotic stress, we evaluated the Drk1 expression during this condition. The hyperosmotic stress, with a sub-lethal concentration of $\mathrm{NaCl}$, leads to a modification of the homogeneous distribution of Drk1 throughout the cell to a clustered accumulation, with a punctuate staining pattern in the cytosol (after $1 \mathrm{~h}$ of $0.15 \mathrm{M}$ $\mathrm{NaCl}$ treatment, a subinhibitory concentration determined through spot assay) (Figure 3B).

Although the lack of consensus in predicting subcellular localization in the in-silico analysis and confocal images does not demonstrate the cell wall localization of the protein, immunogold electron microscopy (EM) showed PbDrk1 is located in P. brasiliensis cell wall (Figure 4). Besides this, EM revealed protein localization in cytoplasm, vacuole, and endoplasmic reticulum (Figure 4). Together, our results showed a random distribution of Drk1 in P. brasiliensis. 
A)

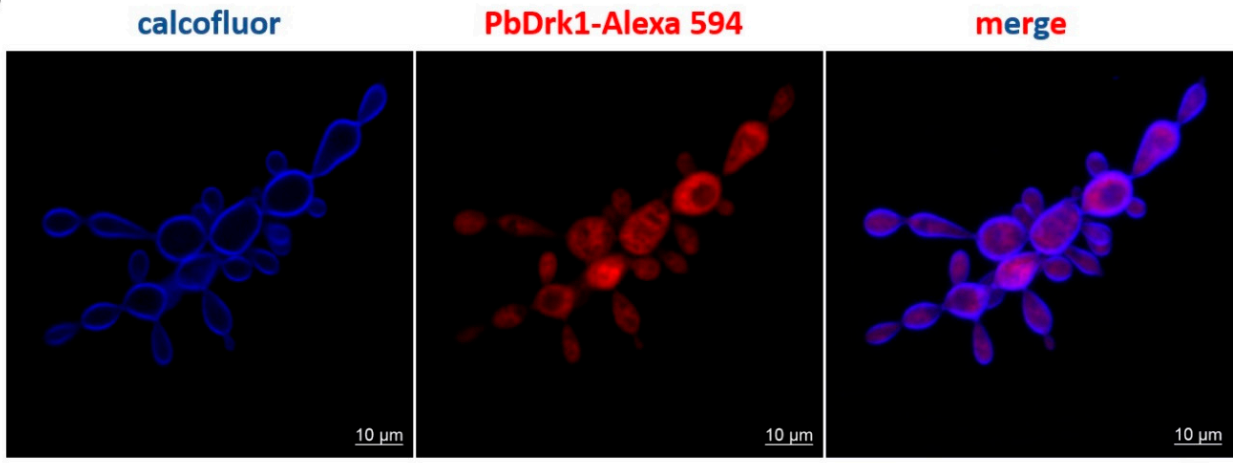

B)

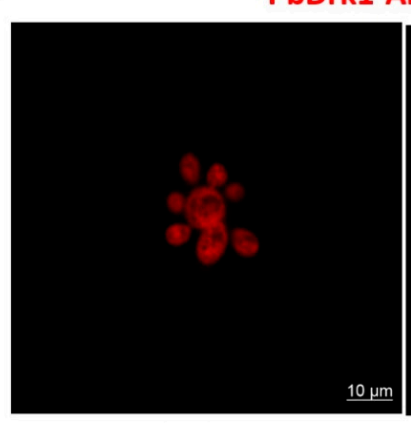

Control
PbDrk1-Alexa 594

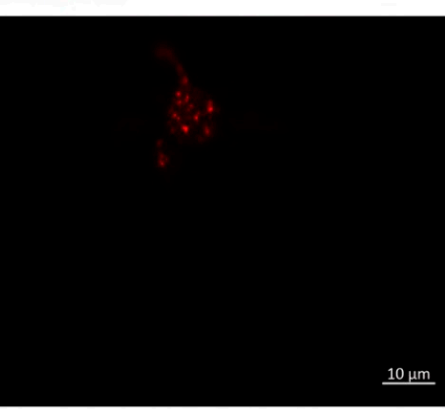

Stress (NaCl)
C)

bright-field

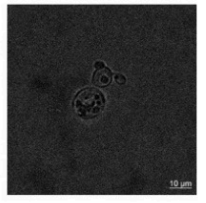

Alexa 594

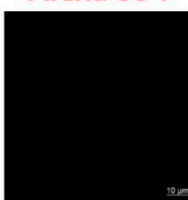

Figure 3. PbDrk1 localization and altered pattern of expression in osmotic stress condition. (A) Confocal microscopy of yeast cells. In blue: calcofluor white staining of the cell wall. In red: reactivity with primary anti-PbDrk1 antibody and anti-rabbit IgG-Alexa 594. (B) Confocal analysis under stress condition $(0.15 \mathrm{M} \mathrm{NaCl})$ and (C) control with secondary antibody alone. Alexa 594: secondary antibody anti-rabbit IgG conjugated with Alexa $594 \mathrm{~nm}$.
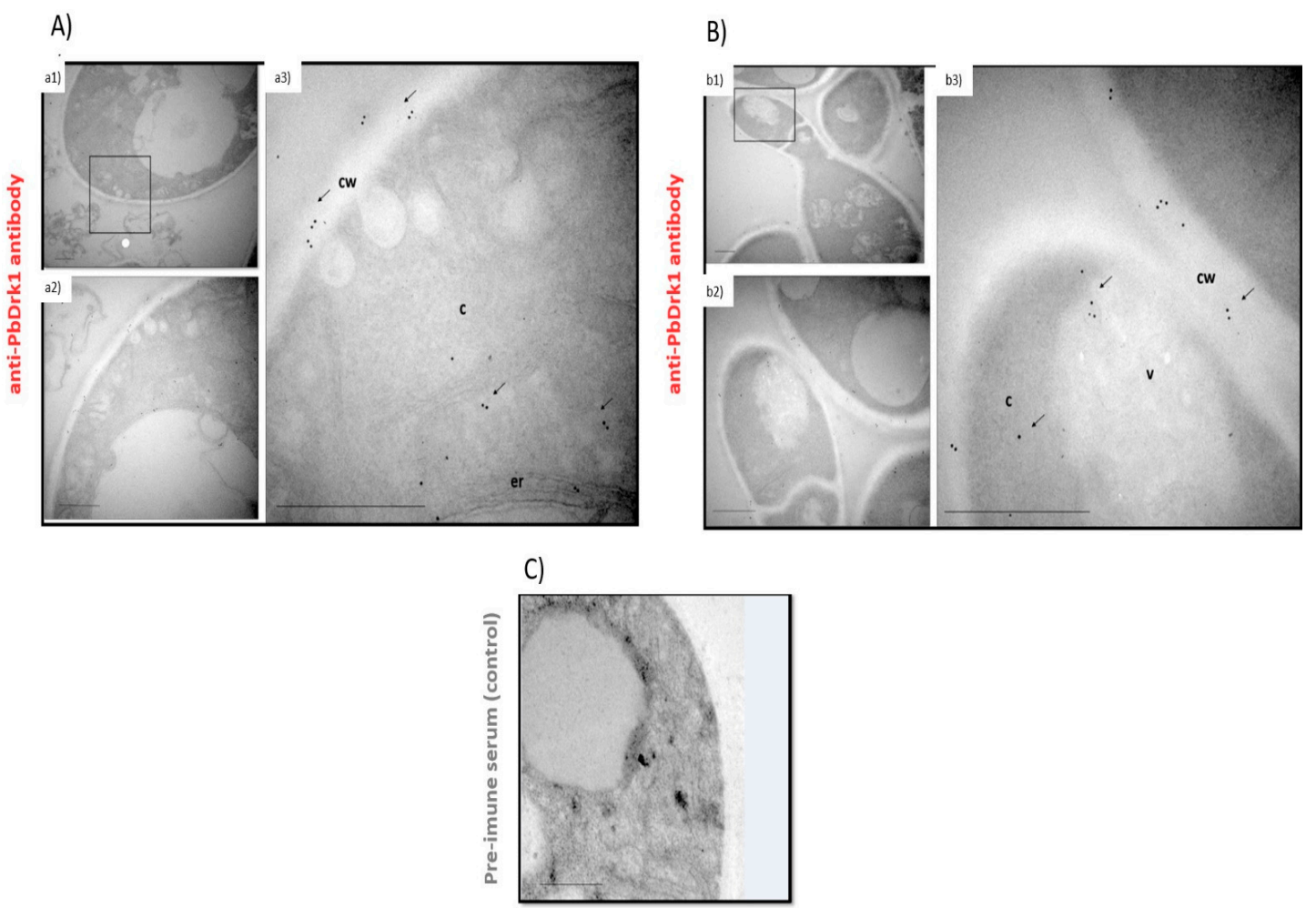

Figure 4. Immunogold analysis of PbDrk1 protein localization in P. brasiliensis yeast cells. The highlighted square in (a1) 
and (b1) points to the P. brasiliensis cell section examined in the differents microscope objectives (a2,a3,b2 and b3). (C) Negative control with non-immune rabbit serum showed no labeling. Abbreviations: cw: cell wall; er: endoplasmatic reticulum; c: cytoplasm; v: vacuole. Scale bars: $1 \mu \mathrm{m}$. Arrows indicate PbDrk1-specific gold particles.

3.4. Inhibition of Drk1 with Anti-PbDrk1 Antibody Alters the Interaction of P. brasiliensis with Pneumocytes and the Fungal Virulence in G. mellonella

The block of PbDrk1 was performed treating P. brasiliensis with anti-PbDrk1 antibody to evaluate the Drk1 importance to the P. brasiliensis-pneumocytes interaction and its virulence in G. mellonella model. The P. brasiliensis treatment with anti-PbDrk1 antibody in the same concentration used in the subsequent assays do not alter the fungal viability (Figure 5A).

A)

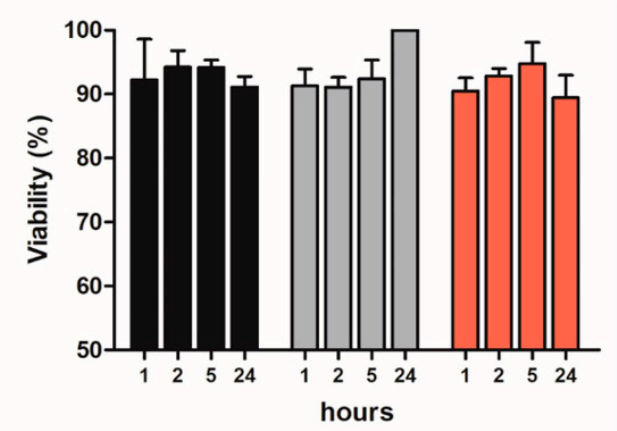

B)

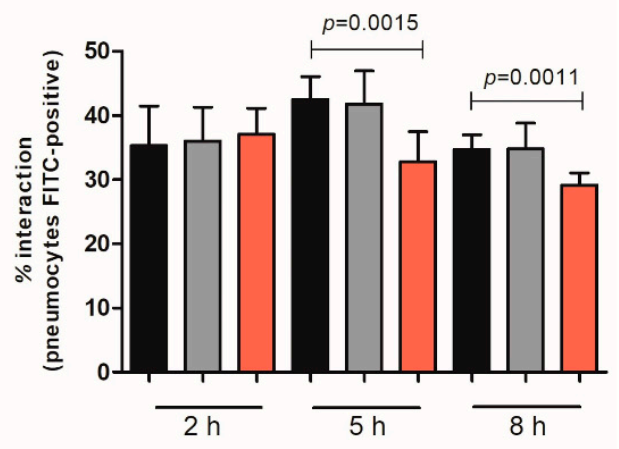

P. brasiliensis without treatment

$P$. brasiliensis + pre-immune serum

P. brasiliensis + anti-PbDrk1 antibody

C)

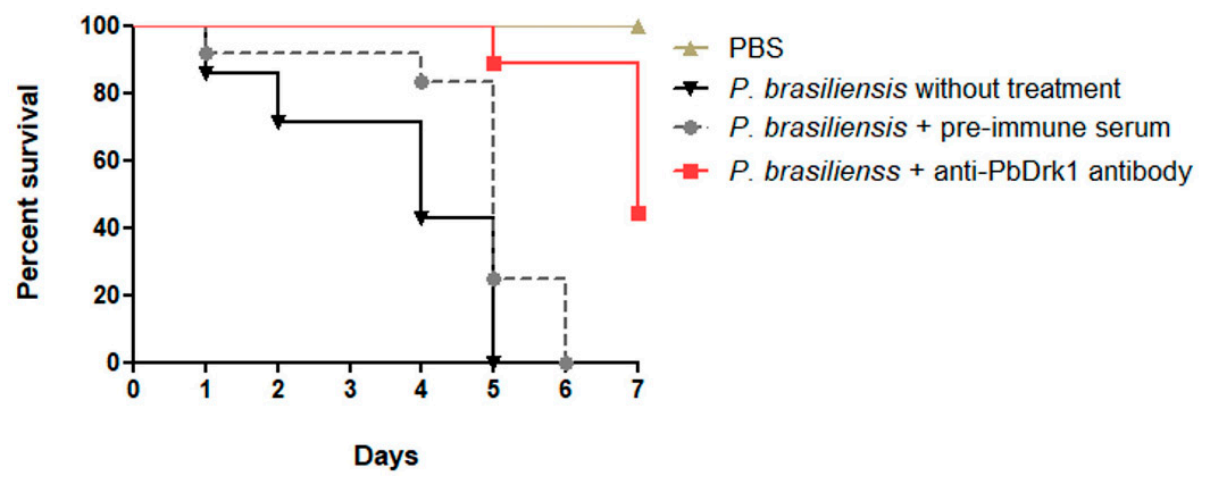

Figure 5. PbDrk1 inhibition and effects on P. brasiliensis-pneumocytes interaction and virulence. P. brasiliensis strain was treated with $20 \mu \mathrm{g} \mathrm{mL}^{-1}$ of anti-PbDrk1 antibody and as control groups we used P. brasiliensis treated with pre-immune serum $\left(20 \mu \mathrm{g} \mathrm{mL}^{-1}\right)$ or untreated. (A) Viability was evaluated for different times $(1,2,5$, and $24 \mathrm{~h})$ by XTT assay. Results are presented as percentage of viability in comparison with the control (P. brasiliensis untreated). (B) P. brasiliensis-interaction with pneumocytes was analyzed 2, 5, and $8 \mathrm{~h}$ after the antibody's treatment by flow cytometry. A total of 10,000 events were counted, and the percentage of pneumocytes-FITC positive (containing yeast cells) was determined. (C) Survival rate of infected G. mellonella ( $n=10$ larvae) infected with P. brasiliensis treated with the anti-PbDrk1 antibody, pre-immune serum control and untreated. Survival was evaluated for seven days. P. brasiliensis treated with anti-PbDrk1 antibody reduces fungus virulence, with a statistically significant difference compared to P. brasiliensis untreated $(p<0.0001)$.

Fungal treatment with anti-PbDrk1 antibody inhibits the interaction (adhesion/invasion) of $P$. brasiliensis with pneumocytes, particularly at 5 and $8 \mathrm{~h}$ of interaction, with a decrease of 1.3-fold and 1.1-fold, respectively (Figure 5B). Regarding the survival rate of G. mellonella (Figure 5C), the block of PbDrk1 led to a significant reduction in virulence, as seen in P. brasiliensis treated with the anti-PbDrk1 antibody that showed a survival rate of $44.4 \%$ at 
the end of experiment (7 days). Additionally, at 5 and 6 days of infection the anti-PbDrk1 treatment resulted in a survival rate of $88.8 \%$ compared to $0 \%$ of the untreated $P$. brasiliensis and treated with pre-immune serum control. Control group of larvae that received PBS showed $100 \%$ of survival at the end of the experiment (Figure 5C). The P. brasiliensis treatment with pre-immune serum showed no difference compared to $P$. brasiliensis without antibody treatment to viability, interaction ability, or virulence in G. mellonella (Figure 5).

\subsection{PbDRK1 Knockdown Does Not Change the Growth Rate and Viability of P. brasiliensis}

To perform a more in-depth evaluation of the relevance of Drk1, we verify whether its deficiency could influence some aspects of $P$. brasiliensis biology and virulence. To this proposal, antisense RNA (aRNA) methodology with ATMT was applied (Figure 6A). $P$. brasiliensis transformation was confirmed through the observation of the presence of $\mathrm{HPH}$ gene in the hygromycin-resistant clones (Figure 6B), indicating the presence of the TDNA cassette in the genomic DNA. Then, the Drk1 transcripts quantification was evaluated by qRT-PCR in the three isolates of hygromycin-resistant strains (PbDRK1 aRNAs: PbDRK1 aRNA2, PbDRK1 aRNA3, and PbDRK1 aRNA4) that revealed a 71.3, 50.3, and 32.5\% lower expression than $\mathrm{PbWT}$, respectively. This result confirmed the efficiency of the methodology in generating $P$. brasiliensis clones to down express DRK1. As expected, the control PbEV does not show a difference in DRK1 expression compared to the PbWT strain (Figure 6C). Despite the efficiency of the gene silencing used, the PbDRK1 aRNAs strains showed a similar growth rate in the BHI medium (1\% glucose) (Figure 6D). Besides this, all strains had comparable viability at the time 0 and $168 \mathrm{~h}$, at the beginning and end of the growth curve.

A)

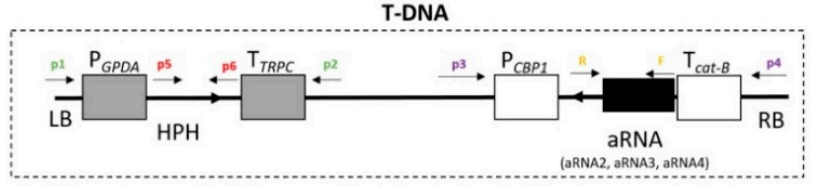

B)

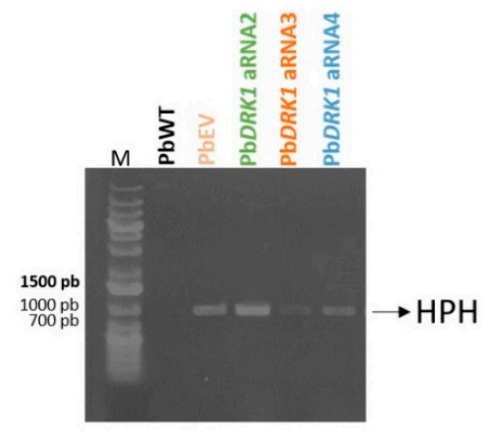

D)

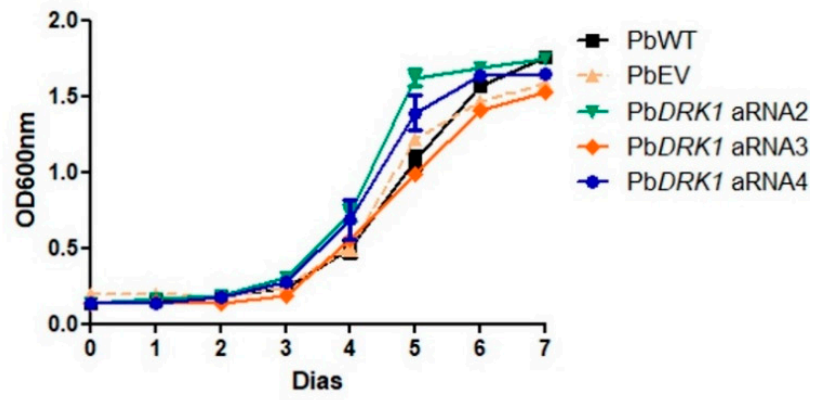

Figure 6. Knockdown of DRK1 of P. brasiliensis. (A) Transfer DNA (T-DNA) construct (carried out in the pUR5750 vector) for aRNA silencing of DRK1 via ATMT, containing the HPH (hygromycin B phosphotransferase) gene driven by the Aspergillus nidulans GPDA (glyceraldehyde 3-phosphate) promoter and TRPC (transcriptional terminator) with aRNA oligonucleotides under the control of CBP1 (calcium-binding protein) promoter from $H$. capsulatum and cat-B gene from Aspergillus fumigatus. (B) After selecting stable mitotic clones, hygromycin-resistant, three isolates (PbDRK1 aRNA2, PbDRK1 
aRNA3, and PbDRK1 aRNA4) were selected, and the HPH gene amplification by PCR was performed to confirm the presence of T-DNA. (C) The relative DRK1 expression levels in the PbDRK1 aRNAs were determined by qRT-PCR compared to $\mathrm{PbWT}$ (that was set at 100\%). The L34 reference gene was used as an endogenous control to normalize the relative DRK1 expression levels. (D) Growth of PbWT, PbEV, and $\mathrm{PbDRK} 1$ aRNA strains. Yeasts from all strains were cultivated at $37^{\circ} \mathrm{C}$ for seven days, and the growth curve profiles were determined by reading the optical density at $600 \mathrm{~nm}$ every $24 \mathrm{~h}$.

\subsection{DRK1 Deficiency Alters the Morphology of P. brasiliensis, Resulting in Elongated Yeast Cells \\ The strains were grown in BHI medium for $72 \mathrm{~h}$, at $37^{\circ} \mathrm{C}(150 \mathrm{rpm})$, to observe morphological alterations resulting from DRK1 silencing and then were examined by scanning electron microscopy. The PbDRK1 aRNA strains showed differences in the yeast morphology with pseudohyphal growth and mother cells more elongated. In addition, the $\mathrm{PbDRK1}$ aRNA strain, which has lower Drk1 expression, better accentuated the described phenotype (Figure 7).}
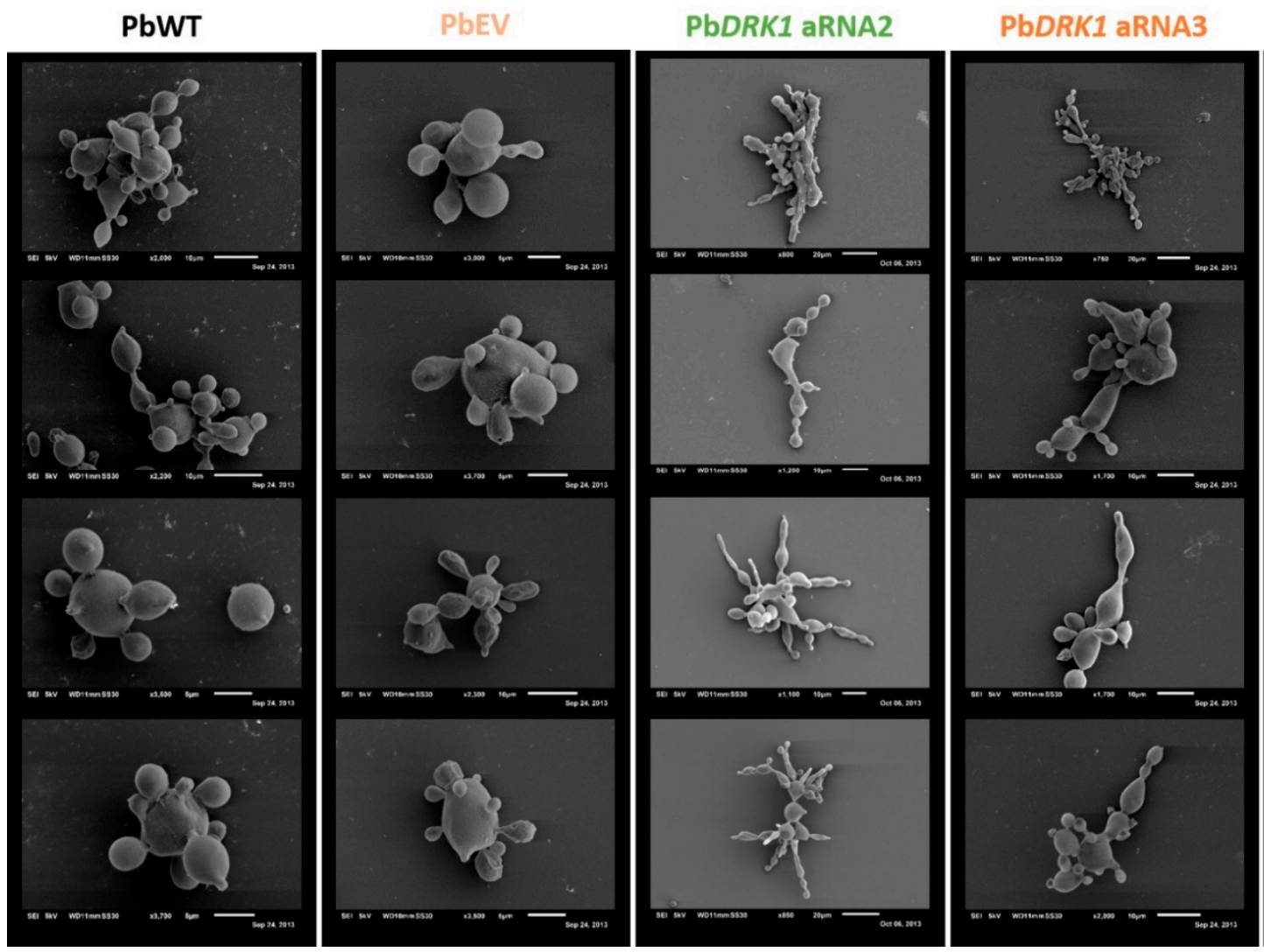

\section{$\mathrm{PbDRK1}$ aRNA4}

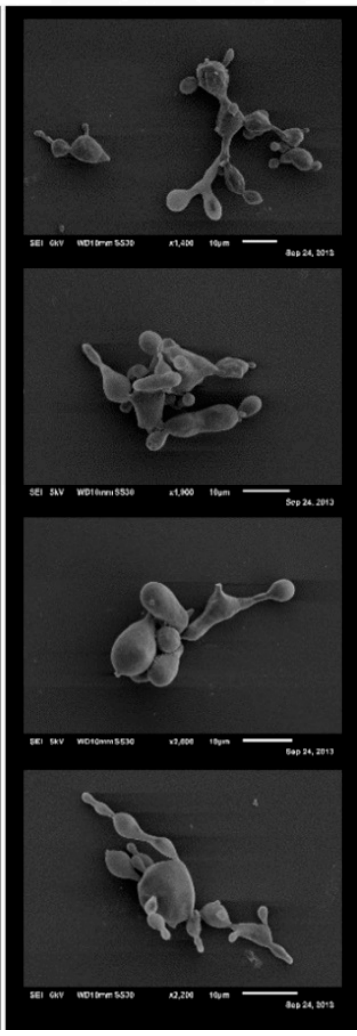

Figure 7. DRK1 is required for normal yeast morphology. The panel illustrates the morphological phenotype of PbWT, $\mathrm{PbEV}, \mathrm{PbDRK1}$ aRNA2, PbDRK1 aRNA3, and PbDRK1 aRNA4 yeast cells with scanning electron microscopy, all strains cultured for $72 \mathrm{~h}$ in liquid BHI medium ( $1 \%$ glucose) at $37^{\circ} \mathrm{C}(150 \mathrm{rpm})$. Scale bars are indicated in each figure.

\subsection{PbDRK1 Silence Affects the Virulence of P. brasiliensis in G. mellonella Model}

The percentage of surviving larvae at day 4 after infection was $41.7,56.2$, and $23.52 \%$ to $\mathrm{PbDRK1}$ aRNA2, $\mathrm{PbDRK1}$ aRNA3, and $\mathrm{PbDRK1}$ aRNA4, respectively, while infection with $\mathrm{PbWT}$ and $\mathrm{PbEV}$ resulted in 100 and $82.4 \%$ of death, respectively. Besides this, the virulence attenuation was more evident to $\mathrm{PbDRK1}$ aRNA2 and $\mathrm{PbDRK1}$ aRNA3, which shows the high degree of DRK1 silencing (Figure 8). 


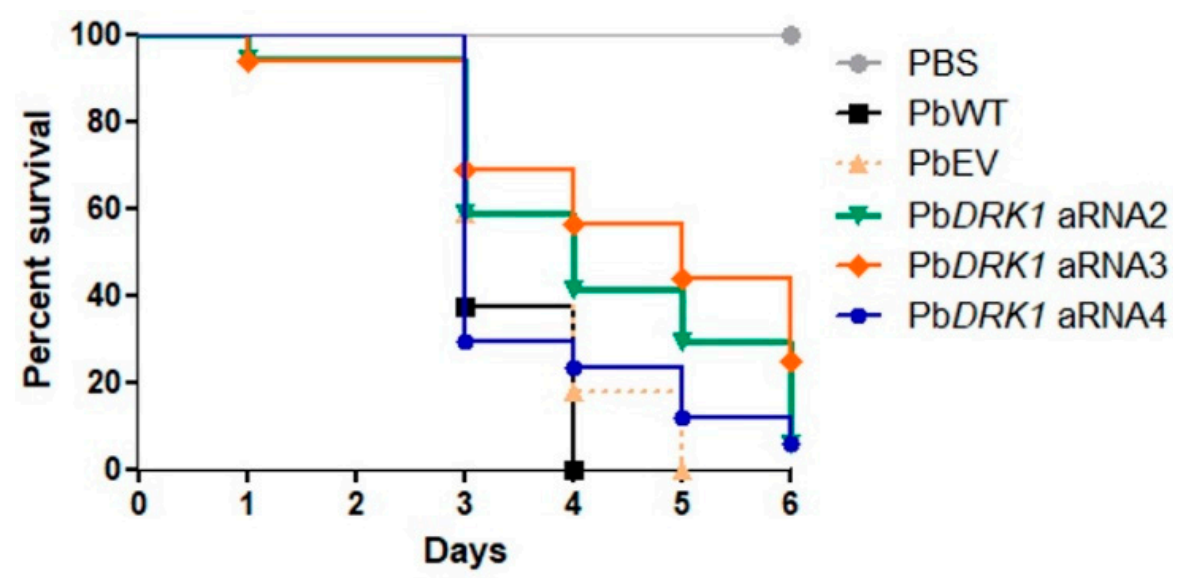

Figure 8. Knockdown of DRK1 expression confers a less virulent profile to P. brasiliensis. Survival curve of $G$. mellonella infected with $5 \times 10^{6}$ cells of the strains, PbWT, PbEV, PbDRK1 aRNA2, PbDRK1 aRNA3, and PbDRK1 aRNA4, incubated at $37^{\circ} \mathrm{C}$, and the death monitored daily. PbWT vs. PbDRK1 aRNA2, $p=0.0226$; PbWT vs. PbDRK1 aRNA3, $p=0.0025$; PbEV vs. PbDRK1 aRNA3, $p=0.0185$; at the end of experiment ( $n=17$ larvae).

\subsection{DRK1 Silencing Change the Chitin Level/Distribution in P. brasiliensis}

Besides the morphological differences in PbDRK1 aRNAs yeast cells, comparing the chitin amount/distribution, it was possible to visualize an aberrant pattern of chitin distribution with some delocalization of the same along with the yeast cells (Figure 9A) with a reduction of chitin amount in P. brasiliensis cell wall, being this reduction 2.35-fold, 2.14-fold, and 1.26-fold to $\mathrm{PbDRK1}$ aRNA2, PbDRK1 aRNA3, PbDRK1 aRNA4, respectively, compared to PbWT (Figure 9B). Furthermore, the greatest decrease in chitin correlated with the highest degree of DRK1 silencing.

3.9. Response to Osmotic Stress, Cell Wall Stressors and Antifungals Can Change due to Reduced Expression of Drk1 in P. brasiliensis

We observed that DRK1 silencing confers a phenotype more tolerant to Congo red (CR) and $\mathrm{NaCl}$ as shown in Figure 10A. The MIC was considered the lowest concentration to the antifungal susceptibility that resulted in a 50\% reduction in fungal growth. Itraconazole PbEV showed a MIC of $0.002 \mu \mathrm{g} \mathrm{mL}^{-1}$ in contrast to $0.001 \mu \mathrm{g} \mathrm{mL}^{-1}$ for PbDRK1 aRNA strains; comparing the viability reduction to $0.0001 \mu \mathrm{g} \mathrm{mL} \mathrm{m}^{-1}$ of ITZ, it was possible to see a decrease of $15.6 \%$ to the PbEV, and $83.5 \%, 61.19 \%$, and $48.2 \%$ to PbDRK1 aRNA2, aRNA3, and aRNA4 respectively, showing that the Drk1-silenced strains appear to be more sensitive to ITZ. In contrast, for caspofungin, PbWT showed a MIC of $4 \mu \mathrm{g} \mathrm{mL}{ }^{-1}$ and the Drk1-silenced strains $16 \mu \mathrm{g} \mathrm{mL}^{-1}$, demonstrating that the Drk1-silenced strains appear to be more tolerant to CSP (Figure 10B). Possibly these results suggest that cell wall composition alterations in the $\mathrm{PbDRK1}$ aRNA strains may render it more resistant to damage by osmotic stress and cell wall disrupting agents. 
A)

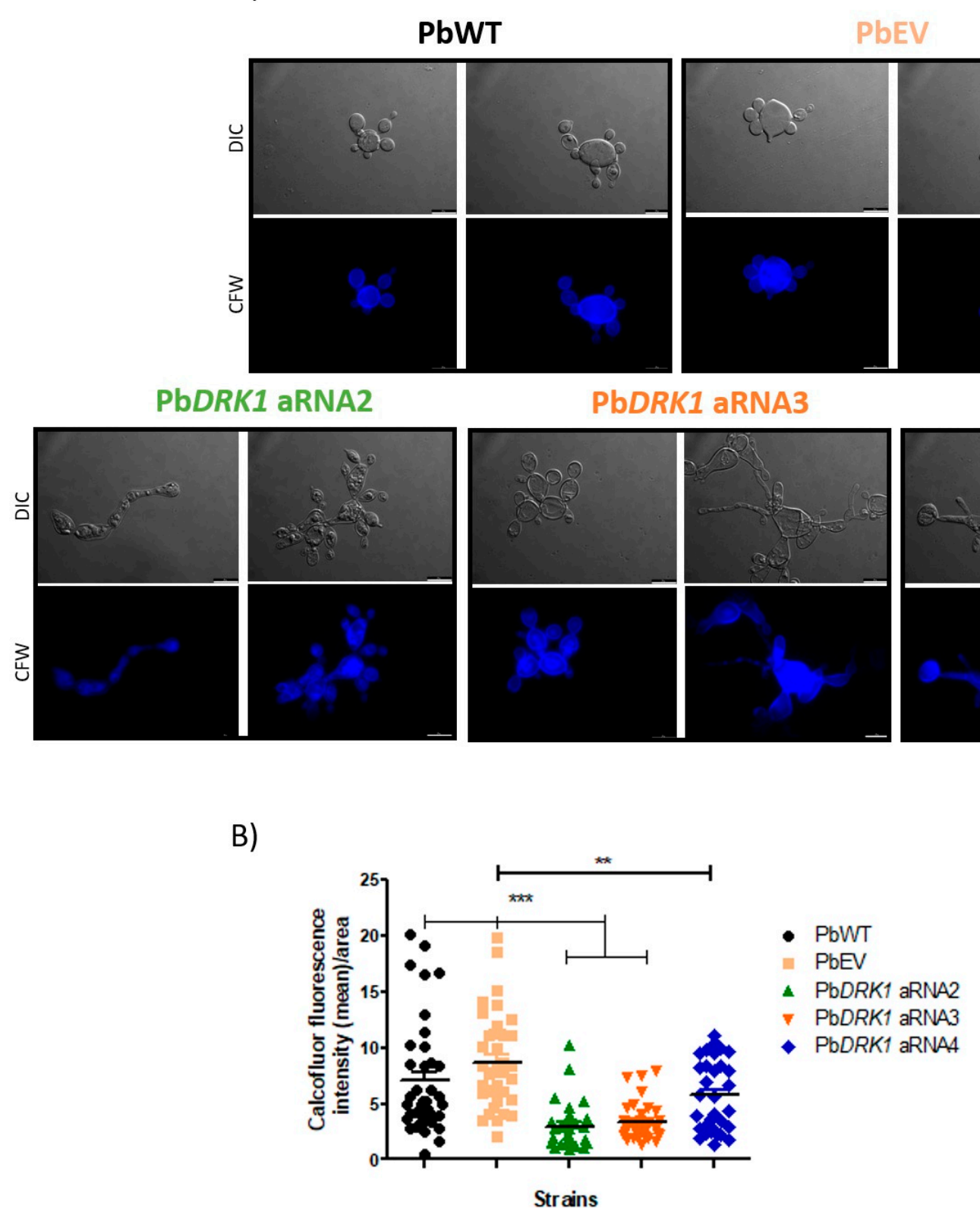

Figure 9. The level of DRK1 expression reduction correlates with a greater reduction of chitin in P. brasiliensis. Yeast cells of $\mathrm{PbWT}, \mathrm{PbEV}$, and PbDRK1 aRNA strains grown for $72 \mathrm{~h}$ at $37^{\circ} \mathrm{C}$ in $\mathrm{BHI}$ medium (1\% glucose) (150 rpm). Paraformaldehydefixed cells were stained with calcofluor white $\left(50 \mu \mathrm{g} \mathrm{mL}^{-1}\right)$ for $1 \mathrm{~h}$ at $\mathrm{RT}$, and after several washes with PBS were (A) visualized under fluorescence microscopy, DMi8 (Leica) and images processed with LasAF software. Scale bars: $10 \mu \mathrm{m}$. (B) The chitin amount was estimated by measuring the calcofluor fluorescence intensity (mean)/area of each cell using ImageJ software. ${ }^{* *} p<0.0001$ and ${ }^{* *} p<0.001$. 
A)

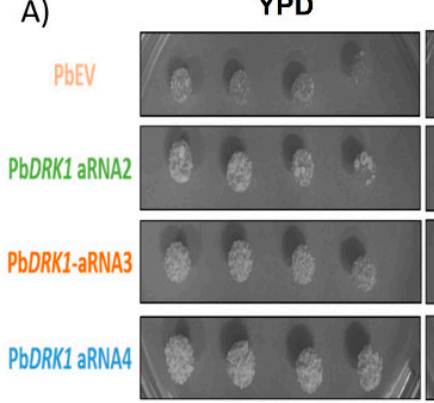

B)
$2.5 \mu \mathrm{g} / \mathrm{mL} \mathrm{CR}$

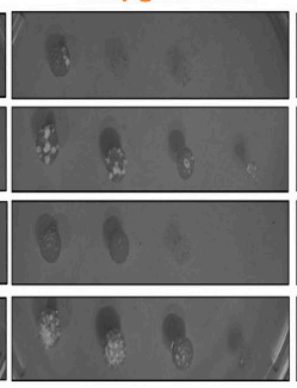

itraconazole

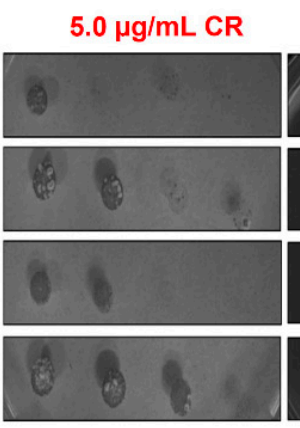

$0.05 \mathrm{M} \mathrm{NaCl}$
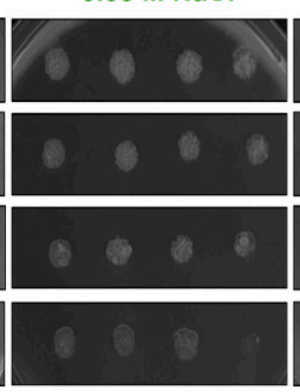

caspofungin

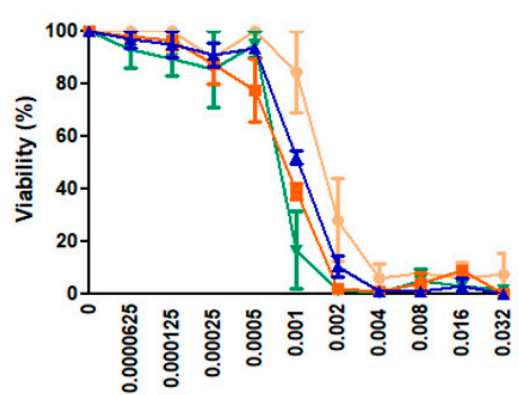

$\mu \mathrm{g} \mathrm{mL}-1$

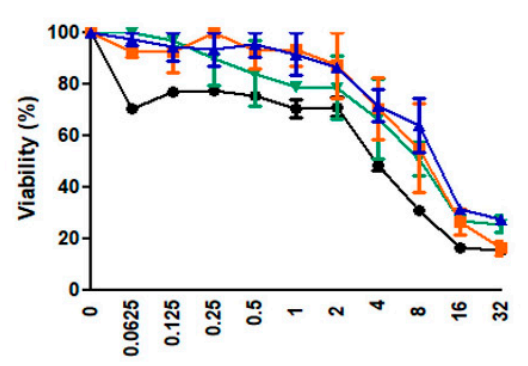

$\mu \mathrm{g} \mathrm{mL^{-1 }}$

- PbWT $\rightarrow$ PbEV $\quad$ PbDRK1 aRNA2

- PbDRK1 aRNA3

- $\mathrm{PbDRK} 1$ aRNA4

Figure 10. DRK1 down expression resulted in altered sensibility to osmotic, cell wall stressors, and antifungals. (A) PbDRK1 aRNA strains are more tolerant to the cell wall and osmotic stress. Ten-fold dilutions of cells were spotted onto YPD agar plates with the indicated concentrations of Congo red (CR) and $\mathrm{NaCl}$. Plates were incubated at $37^{\circ} \mathrm{C}$ for 7 days before being photographed. (B) DRK1 depletion leads to altered sensibility to itraconazole and caspofungin dose-response curves of antifungals against $\mathrm{PbWT}, \mathrm{PbEV}$, and $\mathrm{PbDRK} 1 \mathrm{aRNA}$ strains.

\section{Discussion}

This report described the phenotypic effect of blockage and silencing of the P. brasiliensis Drk1 protein. The silencing of this gene in B. dermatitidis, H. capsulatum, S. schenkii, and T. marneffei suggested that Drk1 protein has a complex role in cell wall integrity, fungal morphogenesis, and virulence $[1,20,22]$ and leads us to show the importance of this protein to P. brasiliensis. P. brasiliensis Drk1 shows high similarity, over $80 \%$, among other fungi of Ascomycetes genus as B. dermatitidis, H. capsulatum, S. schenckii, and Coccidioides immitis [23]. In P. brasiliensis, Chaves et al. [23] demonstrated upregulation of this protein during the transition to yeast phase and osmotic stress, and more expressed in strains with a high virulent profile.

Our results showed P. brasiliensis Drk1 presence in several cell compartments as cytoplasm, vacuole, endoplasmic reticulum, and cell wall. Most hybrid histidine kinases (HHKs) are not predicted to be localized on the cell surface due to the lack of transmembrane domain $[43,44]$. However, Chaves et al. [23], through in silico analysis, indicated that PbDrk1 presents a signal peptide and possibly is an integral transmembrane protein that can explain its translocation to the cell surface in P. brasiliensis, as we observed in our microscopic analysis, where it can sense environment signals translating them into an intracellular input signals for others intracellular HHKs.

The fungal treatment with anti-Drk1 antibody reduced P. brasiliensis to interact with pneumocytes and reduced the virulence in G. mellonella, and we hypothesized that somehow Drk1 could act in the regulation of factors critical to the fungal-host interaction in P. brasiliensis. A less virulent profile was also observed in G. mellonella model to the $\mathrm{PbDRK1}$ aRNA strains, confirming the importance of Drk1 to P. brasiliensis virulence. These findings are consistent with that observed for B. dermatitidis, H. capsulatum, and S. schenckii, in 
which Drk1-silencing markedly reduced pathogenicity [1,22]. An explanation can be that in $B$. dermatitidis and H. capsulatum, the DRK1-mutant have a reduction in the expression of essential adhesins, BAD- 1 that is important adhesin to the interaction of $B$. dermatitidis with macrophages [1,45], and CBP-1 important to H. capsulatum intracellular survival and replication $[1,46,47]$. Besides this, for both species, a reduction in the expression of AGS1 [1], a protein involved in the $\alpha-1,3$ glucan synthesis and also fungal virulence, participates in the pathogenesis since it is able to hide the $\beta$-glucans avoiding the host cell detection [48]. Drk1 may sense host factors, triggering signaling pathway activation that results in gene expression modulation, mainly genes important to the host-fungal interaction.

DRK1 downregulation did not alter the viability or growth rate of P. brasiliensis; however, it affects the yeast cell morphology. Morphological analysis revealed that $P$. brasiliensis DRK1 is essential to maintaining regular yeast shapes of cells; DRK1-silencing cells display a more elongated shape showing a morphology that resembles pseudohyphae. The same phenotype was also observed in B. dermatitidis and H. capsulatum [1]. The maintenance of yeast morphology is of great importance; the morphological change from mycelium to yeast and its maintenance is directly linked to virulence [1].

Our results showed that $P$. brasiliensis exposition to $\mathrm{NaCl}$ resulted in an altered pattern of Drk1 expression in the cells, with its homogeneous distribution tending in average conditions to an aggregated punctuation disposition in the cytoplasm. This phenomenon was also observed in Candida guilliermondi to Nik1 (homologous to Drk1) and can indicate that the protein could be associated with osmotic stress signaling [49].

DRK1-silenced strains are more tolerant to cell-wall perturbing agent Congo red and $\mathrm{NaCl}$. This result is in contrast to that found for B. dermatitis in which DRK1-knockdown strain displays increased sensitivity to Congo red [1]; but similar to that found to the homologous NikA in Aspergillus fumigatus, with NikA mutation conferring resistance to the same cell wall stressor [50]. For B. dermatitidis, DRK1-silenced strain can respond to $\mathrm{NaCl}$ by Hog1 phosphorylation, indicating that Drk1 is not required to respond to salt stress [51], unlike to P. marneffei in which the DrkA deletion (homologous to Drk1) confers increased sensibility to $\mathrm{NaCl}$ [20]; indicating that Drk1 or its homologous plays roles that are not so conserved and therefore vary according to the species.

Chaves et al. [23] showed an increased sensibility to $\mathrm{NaCl}$ after $P$. brasiliensis treatment with iprodione, a fungicide known to inhibit class III of HHKs and therefore Drk1, activating constitutively the HOG pathway (but with the mode of action poorly understood); these data possibly are not comparable with those found in our study, in which $\mathrm{PbDRK1}$ strains are more tolerant to osmotic stress, because recently it was demonstrated that fludioxonil, another fungicide, that also inhibits Drk1, shows its effects in the fungi changing the Drk1 behavior from kinase to phosphatase [51].

The increased resistance to Congo red in P. brasiliensis DRK1-silenced strains could be a consequence of considerable differences in polymer organization and cell wall content. The silencing of DRK1 in P. brasiliensis, rendered to the yeast cells a loss amount and different distribution of chitin, being this reduction correlated with the degree of silencing among the PbDRK1 aRNA strains, indicating that the Drk1 protein can participate in maintaining the cell wall integrity. An aberrant striated pattern of chitin in P. marneffei and B. dermatitidis DRK1-silenced strain was also observed $[1,20]$. In S. cerevisiae it has already been shown that mutant cells tolerant to Congo red exhibit a lower amount of chitin on the cell surface [52,53].

There is evidences reporting the caspofungin tolerance in laboratory strains and this has been associated as a cell wall salvage mechanism; with the fungi increasing the chitin production to compensate the decreased amount of $\beta-1,3$ glucan when glucan synthase is inhibited by this antifungal [54]. The mice infection with C. albicans in which the chitin synthesis was induced by calcium and calcofluor demonstrated that these cells are less susceptible to echinocandin compared to those with normal chitin amount [55]. In C. albicans the caspofungin treatment leads to the activation of Hog $1 p$ to control the oxidative and osmotic stresses that occur due to the exposure to this drug [56], and itraconazole also 
induced oxidative stress $[57,58]$. Therefore, we evaluated the susceptibility of $P$. brasiliensis DRK1-silenced strains to caspofungin and itraconazole, making it possible to assess whether changes in the silenced strains leads to a cell wall compensatory mechanism to balance its structure [54] or even to analyze the DRK1-silenced strain adaptation during the stress condition triggered by antifungals. It was possible to verify that $P$. brasiliensis DRK1-silenced strains seem to be more sensitive to itraconazole, indicating that possibly the oxidative stress triggered by this drug can be sensed by Drk1, and that the tolerance to caspofungin can occur in a way unrelated to the reduced amount of chitin. This question needs to be further evaluated.

\section{Conclusions}

In summary, our findings suggest the involvement of Drk1 in several aspects of $P$. brasiliensis such as maintenance of yeast cell morphology, cell wall composition, response to environmental stresses, and as a cell wall destabilizing drug, host-cell interaction, and virulence. However, several questions are worthy of further investigation such as what signals from the environment are sensed. Evaluation of potential receptors and downstream components that can interact with Drk1, to help in the elucidation of the mechanisms responsible for these changes that can shed light on the pathogenesis of P. brasiliensis at a molecular level, as well as the development of new therapies, once humans lack homologs to Drk1 needs to be done. This protein represents a potential target to treat PCM and other dimorphic fungal diseases.

Supplementary Materials: The following are available online at https:/ /www.mdpi.com/article/10 .3390/jof7100852/s1. Figure S1. PbDrk1 identity confirmation. Mascot results. Peptide summary report of identified protein. Matched peptides are highlighted in red, in which its sequence coverage reaches $59 \%$ of the Drk1 sequence of $P$. brasiliensis.

Author Contributions: Conceptualization, C.M.M., A.M.F.-A. and M.J.S.M.-G.; methodology, C.M.M., H.C.d.O., P.A.A. and R.F.C.; formal analysis, C.M.M., H.C.d.O., P.A.A. and R.F.C.; writing-original draft preparation, C.M.M. and M.J.S.M.-G.; writing—review and editing, C.M.M. and M.J.S.M.-G.; supervision, M.J.S.M.-G.; project administration, M.J.S.M.-G.; funding acquisition, M.J.S.M.-G. All authors have read and agreed to the published version of the manuscript.

Funding: This research was funded by the Brazilian organizations Fundação de Amparo à Pesquisa do Estado de São Paulo (FAPESP) [2016/17048-4 (CMM), 2015/03700-9 (MM-G), 2015/14023-8 (HdO)], Rede Nacional de Métodos Alternativos-Conselho Nacional de Desenvolvimento Científico e Tecnológico (RENAMA-CNPq) [403586/2012-7], Conselho Nacional de Desenvolvimento Científico e Tecnológico (CNPq) [164217/2020-7], Coordenação de Aperfeiçoamento Pessoal de Nível Superior (CAPES) [88881.141306/2017-01] and Programa de Apoio ao Desenvolvimento Científico da Faculdade de Ciências Farmacêuticas da UNESP PADC-FCF-UNESP.

Institutional Review Board Statement: Animal experiments were carried out with full compliance with the Brazilian Federal Law 11 794. All animal procedures were approved by the Ethics Committee on Animal Experiments of the Faculty of Pharmaceutical Sciences of Araraquara-UNESP (Proc.10/2011/CEUA/FCF).

Informed Consent Statement: Not applicable.

Data Availability Statement: The raw data supporting the conclusions on this article will be made available by the authors, without undue reservations, but all relevant data are within the paper.

Acknowledgments: The authors would like to thank the multi-user Flow Cytometry Laboratory at the Núcleo de Proteômica of the Faculty of Pharmaceutical Sciences at UNESP in Araraquara.

Conflicts of Interest: The authors declare no conflict of interest.

\section{References}

1. Nemecek, J.C.; Wüthrich, M.; Klein, B.S. Global Control of Dimorphism and Virulence in Fungi. Science 2006, 312, 583-588. [CrossRef]

2. Klein, B.S.; Tebbets, B. Dimorphism and virulence in fungi. Curr. Opin. Microbiol. 2007, 10, 314-319. [CrossRef] 
3. Muñoz, J.F.; McEwen, J.G.; Clay, O.K.; Cuomo, C.A. Genome analysis reveals evolutionary mechanisms of adaptation in systemic dimorphic fungi. Sci. Rep. 2018, 8, 1-13. [CrossRef] [PubMed]

4. Marques-Da-Silva, S.H.; Rodrigues, A.M.; Silveira-Gomes, F.; de Hoog, G.S.; de Camargo, Z.P. Occurrence of Paracoccidioides lutzii in the Amazon Region: Description of Two Cases. Am. J. Trop. Med. Hyg. 2012, 87, 710-714. [CrossRef]

5. Martinez, R. Epidemiology of Paracoccidioidomycosis. Rev. Inst. Med. Trop. São Paulo 2015, 57, 11-20. [CrossRef] [PubMed]

6. Romani, L. Immunity to fungal infections. Nat. Rev. Immunol. 2004, 4, 11-24. [CrossRef]

7. Casadevall, A.; Pirofski, L.-A. Host-Pathogen Interactions: Redefining the Basic Concepts of Virulence and Pathogenicity. Infect. Immun. 1999, 67, 3703-3713. [CrossRef]

8. Cooney, N.M.; Klein, B.S. Fungal adaptation to the mammalian host: It is a new world, after all. Curr. Opin. Microbiol. 2008, 11, 511-516. [CrossRef]

9. Ene, I.V.; Walker, L.A.; Schiavone, M.; Lee, K.K.; Martin-Yken, H.; Dague, E.; Gow, N.; Munro, C.A.; Brown, A.J.P. Cell Wall Remodeling Enzymes Modulate Fungal Cell Wall Elasticity and Osmotic Stress Resistance. mBio 2015, 6, e00986-15. [CrossRef]

10. Jacob, S.; Thines, E. Multistep phosphorelay in fungi: The enigma of multiple signals and a limited number of signaling pathways. Mycol. Prog. 2017, 16, 1007-1013. [CrossRef]

11. Smith, D.A.; Nicholls, S.; Morgan, B.A.; Brown, A.J.; Quinn, J. A Conserved Stress-activated Protein Kinase Regulates a Core Stress Response in the Human Pathogen Candida albicans. Mol. Biol. Cell 2004, 15, 4179-4190. [CrossRef] [PubMed]

12. Stock, A.M.; Robinson, V.L.; Goudreau, P.N. Two-Component Signal Transduction. Annu. Rev. Biochem. 2000, 69, 183-215. [CrossRef] [PubMed]

13. Mascher, T.; Helmann, J.D.; Unden, G. Stimulus Perception in Bacterial Signal-Transducing Histidine Kinases. Microbiol. Mol. Biol. Rev. 2006, 70, 910-938. [CrossRef] [PubMed]

14. Gauthier, G.; Klein, B.S. Insights into Fungal Morphogenesis and Immune Evasion. Microbe Mag. 2008, 3, 416-423. [CrossRef]

15. Saito, H. Regulation of the Osmoregulatory HOG MAPK Cascade in Yeast. J. Biochem. 2004, 136, 267-272. [CrossRef]

16. Catlett, N.L.; Yoder, O.C.; Turgeon, B.G. Whole-Genome Analysis of Two-Component Signal Transduction Genes in Fungal Pathogens. Eukaryot. Cell 2003, 2, 1151-1161. [CrossRef]

17. Defosse, T.A.; Sharma, A.; Mondal, A.K.; de Bernonville, T.D.; Latgé, J.-P.; Calderone, R.; Giglioli-Guivarc'H, N.; Courdavault, V.; Clastre, M.; Papon, N. Hybrid histidine kinases in pathogenic fungi. Mol. Microbiol. 2015, 95, 914-924. [CrossRef]

18. Maeda, T.; Wurgler-Murphy, S.M.; Saito, H. A two-component system that regulates an osmosensing MAP kinase cascade in yeast. Nature 1994, 369, 242-245. [CrossRef]

19. Posas, F.; Wurgler-Murphy, S.M.; Maeda, T.; Witten, E.A.; Thai, T.C.; Saito, H. Yeast HOG1 MAP Kinase Cascade Is Regulated by a Multistep Phosphorelay Mechanism in the SLN1-YPD1-SSK1 “Two-Component" Osmosensor. Cell 1996, 86, 865-875. [CrossRef]

20. Boyce, K.; Schreider, L.; Kirszenblat, L.; Andrianopoulos, A. The two-component histidine kinases DrkA and SlnA are required for in vivo growth in the human pathogen Penicillium marneffei. Mol. Microbiol. 2011, 82, 1164-1184. [CrossRef] [PubMed]

21. Hou, B.; Zhang, Z.; Zheng, F.; Liu, X. Molecular cloning, characterization and differential expression of DRK1 in Sporothrix schenckii. Int. J. Mol. Med. 2012, 31, 99-104. [CrossRef]

22. Zhang, Z.; Hou, B.; Wu, Y.Z.; Wang, Y.; Liu, X.; Han, S. Two-component histidine kinase DRK1 is required for pathogenesis in Sporothrix schenckii. Mol. Med. Rep. 2017, 17, 721-728. [CrossRef] [PubMed]

23. Chaves, A.F.A.; Navarro, M.V.; Castilho, D.G.; Calado, J.C.P.; Conceição, P.M.; Batista, W.L. A conserved dimorphism-regulating histidine kinase controls the dimorphic switching in Paracoccidioides brasiliensis. FEMS Yeast Res. 2016, 16. [CrossRef] [PubMed]

24. Santoni, G.; Lucciarini, R.; Amantini, C.; Jacobelli, J.; Spreghini, E.; Ballarini, P.; Piccoli, M.; Gismondi, A. Candida albicans Expresses a Focal Adhesion Kinase-Like Protein That Undergoes Increased Tyrosine Phosphorylation upon Yeast Cell Adhesion to Vitronectin and the EA.hy 926 Human Endothelial Cell Line. Infect. Immun. 2002, 70, 3804-3815. [CrossRef]

25. Strober, W. Trypan Blue Exclusion Test of Cell Viability. Curr. Protoc. Immunol. 2015, 111, A3.B.1-A3.B.3. [CrossRef] [PubMed]

26. Laemmli, U.K. Cleavage of Structural Proteins during the Assembly of the Head of Bacteriophage T4. Nature 1970, 227, 680-685. [CrossRef]

27. Torres, I.; Hernandez, O.; Tamayo, D.; Muñoz, J.F.; Jr, N.P.L.; García, A.M.; Restrepo, A.; Puccia, R.; McEwen, J.G. Inhibition of PbGP43 Expression May Suggest that gp43 is a Virulence Factor in Paracoccidioides brasiliensis. PLoS ONE 2013, 8, e68434. [CrossRef] [PubMed]

28. Goes, T.; Bailão, E.F.L.C.; Correa, C.R.; Bozzi, A.; Dos Santos, L.I.; Gomes, D.; Soares, C.M.A.; Goes, A.M. New Developments of RNAi in Paracoccidioides brasiliensis: Prospects for High-Throughput, Genome-Wide, Functional Genomics. PLOS Negl. Trop. Dis. 2014, 8, e3173. [CrossRef]

29. Marcos, C.M.; De Oliveira, H.C.; Silva, J.; Assato, P.; Yamazaki, D.S.; Da Silva, R.A.M.; Santos, C.T.; Santos-Filho, N.; Portuondo, D.L.; Giannini, M.J.M.; et al. Identification and characterisation of elongation factor Tu, a novel protein involved in Paracoccidioides brasiliensis-host interaction. FEMS Yeast Res. 2016, 16, fow079. [CrossRef]

30. Bradford, M.M. A Rapid and Sensitive Method for the Quantitation of Microgram Quantities of Protein Utilizing the Principle of Protein-Dye Binding. Anal. Biochem. 1976, 72, 248-254. [CrossRef]

31. Towbin, H.; Staehelin, T.; Gordon, J. Electrophoretic transfer of proteins from polyacrylamide gels to nitrocellulose sheets: Procedure and some applications. Proc. Natl. Acad. Sci. USA 1979, 76, 4350-4354. [CrossRef] [PubMed] 
32. Meshulam, T.; Levitz, S.M.; Christin, L.; Diamond, R.D. A Simplified New Assay for Assessment of Fungal Cell Damage with the Tetrazolium Dye, (2,3)-bis-(2-Methoxy-4-Nitro-5-Sulphenyl)-(2H)-Tetrazolium-5-Carboxanilide (XTT). J. Infect. Dis. 1995, 172, 1153-1156. [CrossRef] [PubMed]

33. Marcos, C.M.; Tamer, G.; De Oliveira, H.C.; Assato, P.A.; Scorzoni, L.; Santos, C.T.; Singulani, J.D.L.; De Silva, J.D.F.; De Almeida, R.; E Silva, A.C.A.D.P.; et al. Down-regulation of TUFM impairs host cell interaction and virulence by Paracoccidioides brasiliensis. Sci. Rep. 2019, 9, 17206-17215. [CrossRef] [PubMed]

34. Scorzoni, L.; E Silva, A.C.A.D.P.; Singulani, J.D.L.; Leite, F.S.; De Oliveira, H.C.; Da Silva, R.A.M.; Fusco-Almeida, A.M.; MendesGiannini, M.J.S. Comparison of virulence between Paracoccidioides brasiliensis and Paracoccidioides lutzii using Galleria mellonella as a host model. Virulence 2015, 6, 766-776. [CrossRef] [PubMed]

35. Almeida, A.; Carmona, J.; Cunha, C.; Carvalho, A.; Rappleye, C.; Goldman, W.; Hooykaas, P.; Leão, C.; Ludovico, P.; Rodrigues, F. Towards a molecular genetic system for the pathogenic fungus Paracoccidioides brasiliensis. Fungal Genet. Biol. 2007, 44, 1387-1398. [CrossRef] [PubMed]

36. Menino, J.; Almeida, A.J.; Rodrigues, F. Gene Knockdown in Paracoccidioides brasiliensis Using Antisense RNA. Methods Mol. Biol. 2012, 845, 187-198. [CrossRef]

37. Cleary, I.A.; MacGregor, N.B.; Saville, S.P.; Thomas, D.P. Investigating the Function of Ddr48p in Candida albicans. Eukaryot. Cell 2012, 11, 718-724. [CrossRef]

38. Livak, K.J.; Schmittgen, T.D. Analysis of Relative Gene Expression Data Using Real-Time Quantitative PCR and the 2- $\Delta \Delta C T$ Method. Methods 2001, 25, 402-408. [CrossRef]

39. Marcos, C.M.; Silva, J.; De Oliveira, H.C.; Assato, P.; Singulani, J.D.L.; Lopez, A.M.; Tamayo, D.P.; Hernandez-Ruiz, O.; McEwen, J.G.; Giannini, M.J.M.; et al. Decreased expression of 14-3-3 in Paracoccidioides brasiliensis confirms its involvement in fungal pathogenesis. Virulence 2016, 7, 72-84. [CrossRef]

40. De Oliveira, H.C.; Joffe, L.S.; Simon, K.S.; Castelli, R.F.; Reis, F.C.G.; Bryan, A.M.; Borges, B.S.; Medeiros, L.C.S.; Bocca, A.L.; Del Poeta, M.; et al. Fenbendazole Controls In Vitro Growth, Virulence Potential, and Animal Infection in the Cryptococcus Model. Antimicrob. Agents Chemother. 2020, 64, e00286-20. [CrossRef]

41. De Paula e Silva, A.C.A.; Oliveira, H.C.; Silva, J.; Sangalli-Leite, F.; Scorzoni, L.; Fusco-Almeida, A.M.; Mendes-Giannini, M.J.S Microplate alamar Blue Assay for Paracoccidioides Susceptibility Testing. J. Clin. Microbiol. 2013, 51, 1250-1252. [CrossRef]

42. Ram, A.F.J.; Klis, F.M. Identification of fungal cell wall mutants using susceptibility assays based on Calcofluor white and Congo red. Nat. Protoc. 2006, 1, 2253-2256. [CrossRef] [PubMed]

43. Fassler, J.S.; West, A.H. Histidine Phosphotransfer Proteins in Fungal Two-Component Signal Transduction Pathways. Eukaryot. Cell 2013, 12, 1052-1060. [CrossRef] [PubMed]

44. Hérivaux, A.; So, Y.-S.; Gastebois, A.; Latgé, J.-P.; Bouchara, J.-P.; Bahn, Y.-S.; Papon, N. Major Sensing Proteins in Pathogenic Fungi: The Hybrid Histidine Kinase Family. PLoS Pathog. 2016, 12, e1005683. [CrossRef]

45. Brandhorst, T.T.; Wüthrich, M.; Warner, T.; Klein, B. Targeted Gene Disruption Reveals an Adhesin Indispensable for Pathogenicity of Blastomyces dermatitidis. J. Exp. Med. 1999, 189, 1207-1216. [CrossRef] [PubMed]

46. Isaac, D.T.; Berkes, C.A.; English, B.C.; Murray, D.H.; Lee, Y.N.; Coady, A.; Sil, A. Macrophage cell death and transcriptional response are actively triggered by the fungal virulence factor $\mathrm{C}$ bp1 during $\mathrm{H}$. capsulatum infection. Mol. Microbiol. 2015, 98, 910-929. [CrossRef] [PubMed]

47. Sebghati, T.S.; Engle, J.T.; Goldman, W.E. Intracellular Parasitism by Histoplasma capsulatum: Fungal Virulence and Calcium Dependence. Science 2000, 290, 1368-1372. [CrossRef]

48. Rappleye, C.; Eissenberg, L.G.; Goldman, W.E. Histoplasma capsulatum -(1,3)-glucan blocks innate immune recognition by the beta-glucan receptor. Proc. Natl. Acad. Sci. USA 2007, 104, 1366-1370. [CrossRef]

49. Foureau, E.; Clastre, M.; Montoya, E.J.O.; Besseau, S.; Oudin, A.; Glévarec, G.; Simkin, A.J.; Crèche, J.; Atehortùa, L.; GiglioliGuivarc'H, N.; et al. Subcellular localization of the histidine kinase receptors Sln1p, Nik1p and Chk1p in the yeast CTG clade species Candida guilliermondii. Fungal Genet. Biol. 2014, 65, 25-36. [CrossRef]

50. Hagiwara, D.; Takahashi-Nakaguchi, A.; Toyotome, T.; Yoshimi, A.; Abe, K.; Kamei, K.; Gonoi, T.; Kawamoto, S. NikA/TcsC Histidine Kinase is Involved in Conidiation, Hyphal Morphology, and Responses to Osmotic Stress and Antifungal Chemicals in Aspergillus fumigatus. PLoS ONE 2013, 8, e80881. [CrossRef]

51. Lawry, S.; Tebbets, B.; Kean, I.; Stewart, D.; Hetelle, J.; Klein, B.S. Fludioxonil Induces Drk1, a Fungal Group III Hybrid Histidine Kinase, To Dephosphorylate Its Downstream Target, Ypd1. Antimicrob. Agents Chemother. 2017, 61, e01414-16. [CrossRef]

52. Omura, F.; Takagi, M.; Kodama, Y. Compromised chitin synthesis in lager yeast affects its Congo red resistance and release of mannoproteins from the cells. FEMS Microbiol. Lett. 2020. [CrossRef]

53. Imai, K.; Noda, Y.; Adachi, H.; Yoda, K. A Novel Endoplasmic Reticulum Membrane Protein Rcr1 Regulates Chitin Deposition in the Cell Wall of Saccharomyces cerevisiae. J. Biol. Chem. 2005, 280, 8275-8284. [CrossRef]

54. Yang, F.; Zhang, L.; Wakabayashi, H.; Myers, J.; Jiang, Y.; Cao, Y.; Jimenez-Ortigosa, C.; Perlin, D.S.; Rustchenko, E. Tolerance to Caspofungin in Candida albicans is Associated with at Least Three Distinctive Mechanisms That Govern Expression of FKS Genes and Cell Wall Remodeling. Antimicrob. Agents Chemother. 2017, 61, e00071-17. [CrossRef]

55. Lee, K.K.; MacCallum, D.M.; Jacobsen, M.D.; Walker, L.A.; Odds, F.C.; Gow, N.A.R.; Munro, C.A. Elevated Cell Wall Chitin in Candida albicans Confers Echinocandin Resistance In Vivo. Antimicrob. Agents Chemother. 2012, 56, 208-217. [CrossRef] 
56. Kelly, J.; Rowan, R.; McCann, M.; Kavanagh, K. Exposure to caspofungin activates Cap and Hog pathways in Candida albicans. Med. Mycol. 2009, 47, 697-706. [CrossRef] [PubMed]

57. Kim, J.H.; Chan, K.L.; Faria, N.C.G.; Martins, M.D.L.; Campbell, B.C. Targeting the Oxidative Stress Response System of Fungi with Redox-Potent Chemosensitizing Agents. Front. Microbiol. 2012, 3, 88. [CrossRef] [PubMed]

58. Lee, W.; Lee, D.G. Reactive oxygen species modulate itraconazole-induced apoptosis via mitochondrial disruption in Candida albicans. Free Radic. Res. 2017, 52, 39-50. [CrossRef] [PubMed] 